\title{
Competitive Behavior in Market Games: Evidence and Theory*
}

\author{
John Duffy \\ University of Pittsburgh \\ Pittsburgh, PA 15260
}

\author{
Alexander Matros \\ University of Pittsburgh \\ Pittsburgh, PA 15260
}

\author{
Ted Temzelides \\ Rice University \\ Houston, TX 77251
}

March 2009

\begin{abstract}
We explore whether competitive outcomes arise in an experimental implementation of a market game, introduced by Shubik (1972). Market games obtain Pareto inferior (strict) Nash equilibria, in which some markets are closed. We find that subjects do not coordinate on autarkic Nash equilibria, but favor more efficient Nash equilibria in which all markets are open. As the number of subjects participating in the market game increases, the Nash equilibrium they achieve approximates the associated Walrasian equilibrium of the underlying economy. Motivated by these findings, we investigate theoretically whether evolutionary forces lead to Walrasian outcomes in market games. We introduce a strong version of evolutionary stable strategies $(S E S S)$ for finite populations. Our concept requires stability against deviations by coalitions of agents. A small coalition of trading agents is sufficient for Pareto-improving trade to be generated. In addition, provided that agents lack market power, Nash equilibria corresponding to approximate competitive outcomes constitute the only approximate SESS.
\end{abstract}

Keywords: Experimental Market Games, Full Nash Equilibrium, Walrasian Equilibrium, Evolutionary Stability.

JEL Codes: C72, C73, C92, D51.

${ }^{*}$ We thank Martin Shubik, Steve Spear and seminar participants at several conferences and universities for useful comments and suggestions on earlier drafts. The usual disclaimer applies. 


\section{Introduction}

Walrasian equilibrium is a cornerstone of modern economics. It is, therefore, not surprising that the question of price formation has received considerable attention in general equilibrium theory. The tâtonnement process has been used extensively in this context. ${ }^{1}$ The study of the tâtonnement, however, has produced largely negative results, and this has led some researchers to conclude that decentralized information about prices alone is not sufficient to bring the economy to a Walrasian equilibrium. In addition, and perhaps more importantly, the tâtonnement process has been criticized for lacking micro-foundations since the price adjustment process is not the outcome of individual optimization.

Even setting the traditional stability question aside, Walrasian behavior may be challenged on the basis of complexity. Can agents learn to behave in such a way that an outside observer of the economy will see a Walrasian equilibrium allocation? We begin this paper by exploring whether agents exhibit behavior consistent with Walrasian equilibrium in a laboratory implementation of a market game, introduced by Shubik (1972). ${ }^{2}$ Market games give rise to competitive outcomes when agents lack market power. Thus, they have served as a non-cooperative foundation for Walrasian outcomes. Even in large economies, however, in addition to approximately Walrasian outcomes, market games obtain Pareto inferior (strict) Nash equilibria, in which some, and possibly all, markets are closed due to a coordination failure. While market games offer an interesting benchmark, to our knowledge there are no attempts to experimentally implement a market game setup. Our work, thus, attempts to fill this gap and is in the spirit of exploring properties of different market structures in the laboratory.

Our experimental findings reveal that subjects placed in a two-good pure exchange market game coordinate away from equilibria where markets are closed (even though such equilibria are strict). Instead, and perhaps more importantly, subjects' play concentrates around efficient "full" Nash equilibria in which markets are open and there is a large volume of trade. We perform comparative statics on the size of the economy and find that, as the number of agents participating in the market game increases, the full Nash equilibria they achieve come closer to approximating the associated Walrasian equilibrium of the underlying economy. Indeed, our findings suggest that if the economy is sufficiently large, the market game mechanism will reliably lead agents to Walrasian equilibrium allocations.

Motivated by these observations, and in order to better understand our experimental findings, we built a theoretical model of a market game played by boundedly rational agents. ${ }^{3}$ We consider a pure exchange

\footnotetext{
${ }^{1}$ See Arrow and Hurwicz (1959) for a classic reference.

${ }^{2}$ There is extensive literature on market games. Standard references include Shapley (1977), Shapley and Shubik (1977), Dubey and Shubik (1977), and Mas-Colell (1982).

3 Our paper reverses the "standard" sequence in experimental economics research, in which an (often existing) theoretical model is implemented experimentally. Instead, we build a theoretical model in order to understand regularities observed in experimental data. We, thus, follow a long tradition established in the natural sciences.
} 
economy with a large, finite number of agents and a finite number of goods as in Postlewaite and Schmeidler (1978). Instead of imposing Nash-behavior, we study this game from an evolutionary point of view. After all, competitive outcomes are often justified by appealing to the natural selection of behavior that is more "fit." ${ }^{4}$ Our story is not explicitly dynamic. Rather, we demonstrate that certain outcomes can be disturbed by the introduction of a small number of "noise-traders," some of whom can become better off in relative terms by choosing different trading patterns. Interestingly, the lack of market power is necessary for this to be true. ${ }^{5}$

We introduce a strong version of evolutionary stable strategies (SESS) for asymmetric, finite games and demonstrate that, in an approximate sense that we make precise, (partial) autarky outcomes are not SESS. Roughly speaking, SESS requires stability against all coalitions consisting of at most one agent per population. In a market game context, a suitable small-size coalition can generate trade and open a market. Thus, evolutionary forces provide an avenue through which the economy can avoid situations where some markets are closed due to a coordination failure. Feasible outcomes in which all markets are open, and in which non-Walrasian prices prevail in some markets, can also be disturbed by a small coalition. More precisely, we demonstrate that, if the game is sufficiently large so that agents' market power is insignificant, Nash equilibria that support approximate Walrasian equilibria of the underlying economy are the only approximate $S E S S$.

The intuition behind our theoretical findings can be summarized as follows. Since a single agent cannot create beneficial trade, Pareto inferior outcomes, in which some markets are closed, cannot be disturbed by the actions of one agent. On the other hand, the introduction of a small number of traders from several sides of the market is sufficient to rule out such outcomes. All other non-Nash states that involve trade, but not necessarily individual optimization, can be disturbed by a single agent who chooses the best basket at given prices. An important ingredient in our analysis is that the number of agents in the economy under study is much greater than the size of the deviating coalition. Consequently, while such coalitions can change certain agents' baskets, they have a small effect on prices. As a result, if the economy is close to a Walrasian equilibrium, no deviations by small-size coalitions can lead to significant improvements. Thus, consistent with the traditionally held view, our findings provide support for the belief that evolutionary forces lead to competitive outcomes, but only when individuals lack market power. ${ }^{6}$

The remainder of the paper is organized as follows. In the next Section we provide a motivating example

\footnotetext{
${ }^{4}$ See Alchian (1950) for one of the first attempts to formalize this argument. Weibull (1995), Vega-Redondo (1996), and Samuelson (1997) provide reviews of evolutionary models.

${ }^{5}$ Our results are related to Dubey and Shubik (1978), who introduce an outside agency that ensures that arbitrarily small amounts of bids and asks are present in all markets. Our argument, however, does not rely on the existence of such an agency. In addition, we impose minimal rationality requirements, and we explicitly consider non-Nash outcomes.

${ }^{6}$ More precisely, the Nash equilibrium in which all markets are open may fail to be evolutionary stable if it does not correspond to an approximate Walrasian equilibrium. This is in contrast with some recent papers in the literature, notably Vega-Redondo (1997).
} 
of a simple, $2 \times 2$ market game that will be used in our experiment. Section 3 details our experimental design and findings. Section 4 contains our theoretical results. We first introduce our solution concept, followed by a description of a general market game. We then state our findings from applying our notion of evolutionary stability. Section 5 relates these findings to the existing literature. A technical Appendix follows.

\section{$2 \quad 2 \times 2$ Market Games}

We begin by presenting a simple example of a market game that is built around an Edgeworth-box-economy with two types of agents and two consumption goods. This example serves two purposes. First, it introduces the main setup on which our experimental design will be based. Second, it motivates some of the issues that we will concentrate on in our theoretical study of more general market games.

There are two populations of equal size, each consisting of $n$ agents. We will refer to agents in the first population as type $I$ and those in the second population as type II. There are two consumption goods, $x$ and $y$. Populations are distinguished by preferences and endowments. Agents of type $i$, where $i \in\{I, I I\}$, have continuous, strictly increasing, strictly convex, smooth preferences denoted by $\succeq^{i}$ and endowment $w^{i}=\left(w_{x}^{i}, w_{y}^{i}\right) \in \mathbb{R}_{++}^{2}$. We shall restrict ourselves to economies with a unique, interior Walrasian equilibrium.

Agents participate in a market game similar to the one introduced by Shapley and Shubik (1977). Each agent can bid a positive amount of one good in exchange for an amount of the other good. The exchange rates, or prices, are determined as the ratios of the aggregate bids for the two commodities.

More precisely, let $b_{j}^{i}$ be the amount of good $j$ bid by agent $i$, and let $B_{j}=\sum_{i=1}^{2 n} b_{j}^{i}$ be the total amount of good $j$ bid by all agents. Bidding takes place according to the following rules. For all agents of type $i$, $i \in\{I, I I\}$, we require that

$$
\begin{gathered}
b_{x}^{i}=0 \text { or } b_{y}^{i}=0, \text { or both, } \\
0 \leq b_{x}^{i} \leq w_{x} \text { and } 0 \leq b_{y}^{i} \leq w_{y} .
\end{gathered}
$$

The first condition requires that agents may bid a positive amount of only one of the two goods. The second condition requires that individual bids are feasible. The consumption baskets in the resulting allocation are determined by the following.

$$
\begin{aligned}
& x^{i}=w_{x}^{i}-b_{x}^{i}+b_{y}^{i} \frac{B_{x}}{B_{y}}, \\
& y^{i}=w_{y}^{i}-b_{y}^{i}+b_{x}^{i} \frac{B_{y}}{B_{x}} .
\end{aligned}
$$

In order to "visualize" the mechanism, one could imagine the existence of a trading post where the total bids of the two goods are aggregated and then the total amount of good $x(y)$ bid is distributed across the 
good $y(x)$ bidders in proportions equal to the relative size of their individual bids. The relative prices of

goods $x$ and $y, p_{x}$ and $p_{y}$, are given by the ratios $\frac{B_{x}}{B_{y}}$ and $\frac{B_{y}}{B_{x}}$, respectively. While these implicit prices are not determined until bids are submitted, in equilibrium agents' expectations of prices will be correct.

A standard approach is to consider the Nash problem that each individual faces in the above game. Assuming that agent $i$ is a bidder of good $x$, this problem can be phrased as follows: given the total bids by the other agents, choose $b_{x}^{i}$ so as to maximize $\succeq^{i}$ subject to constraints (1) - (2), and similarly for bidders of good $y$. Since agents of the same type are identical, it makes sense to consider outcomes where agents of the same type make the same bids and achieve the same allocation. It is straightforward to verify that $b_{x}^{i}=0, b_{y}^{i}=0$ is a strict, "autarkic" Nash equilibrium. Unless the endowment point itself is the Walrasian equilibrium allocation, this equilibrium results in a Pareto inferior outcome. It is also straightforward to verify that there exists another Pareto superior strict Nash equilibrium in which trade occurs. Yet, this equilibrium is not Pareto efficient as agents in a finite game have some market power. This inefficiency diminishes as the number of agents increases. Indeed, the Nash equilibrium with trade approximates the Walrasian allocation of the underlying economy as each agent's bid becomes insignificant relative to the corresponding aggregate bid. We consider a numerical example next.

\subsection{A Symmetric Example}

Assume $n>1$ of each of the two player types, $I$ and $I I$. The two types have the following endowments and preferences over $x$ and $y$ :

$$
w^{I}=(10,200), u^{I}=x^{2} y, \text { and } w^{I I}=(200,10), u^{I I}=x y^{2} .
$$

The corresponding demand functions are given by:

$$
\begin{aligned}
x^{I} & =\frac{2\left(p_{x} w_{x}^{I}+p_{y} w_{y}^{I}\right)}{3 p_{x}}, \\
y^{I} & =\frac{\left(p_{x} w_{x}^{I}+p_{y} w_{y}^{I}\right)}{3 p_{y}}, \\
x^{I I} & =\frac{\left(p_{x} w_{x}^{I I}+p_{y} w_{y}^{I I}\right)}{3 p_{x}}, \\
y^{I I} & =\frac{2\left(p_{x} w_{x}^{I I}+p_{y} w_{y}^{I I}\right)}{3 p_{y}} .
\end{aligned}
$$

Using market clearing and the endowments given in (5), the (unique) competitive equilibrium is given by:

$$
\overline{p_{x}}=\overline{p_{y}}=1 ; \bar{x}^{I}=140 ; \bar{y}^{I}=70 ; \bar{x}^{I I}=70 ; \bar{y}^{I I}=140 .
$$


The Nash problem for agent $i$ of type $I$ (and similarly for a type $I I$ agent) is given by

$$
\begin{aligned}
& \max _{b_{y}^{i} \in\left[0, w_{y}^{I}\right]}\left(10+\frac{b_{y}^{i}}{B_{y}} B_{x}\right)^{2}\left(200-b_{y}^{i}\right) \\
= & \max _{b_{y}^{i} \in\left[0, w_{y}^{I}\right]}\left(10+\frac{b_{y}^{i}}{\left(b_{y}^{i}+\sum_{j \in I, j \neq i} b_{y}^{j}\right)} B_{x}\right)^{2}\left(200-b_{y}^{i}\right) .
\end{aligned}
$$

The FOC for this problem gives

$$
\begin{aligned}
& 2\left[10+\frac{b_{y}^{i}}{\left(b_{y}^{i}+\sum_{j \in I, j \neq i} b_{y}^{j}\right)} B_{x}\right]\left(200-b_{y}^{i}\right) B_{x}\left[\frac{\sum_{j \in I, j \neq i} b_{y}^{j}}{\left(b_{y}^{i}+\sum_{j \in I, j \neq i} b_{y}^{j}\right)^{2}}\right] \\
& -\left[10+\frac{b_{y}^{i}}{\left(b_{y}^{i}+\sum_{j \in I, j \neq i} b_{y}^{j}\right)} B_{x}\right]^{2}=0,
\end{aligned}
$$

and similarly for the type $I I$ agent. The two equations can be solved for the symmetric Nash bids. These are given by

$$
2\left(200-b_{y}^{i}\right) B_{x}\left[\frac{\sum_{j \in I, j \neq i} b_{y}^{j}}{\left(b_{y}^{i}+\sum_{j \in I, j \neq i} b_{y}^{j}\right)^{2}}\right]=10+\frac{b_{y}^{i}}{\left(b_{y}^{i}+\sum_{j \in I, j \neq i} b_{y}^{j}\right)} B_{x},
$$

and

$$
2\left(200-b_{x}^{i}\right) B_{y}\left[\frac{\sum_{j \in I I, j \neq i} b_{x}^{j}}{\left(b_{x}^{i}+\sum_{j \in I I, j \neq i} b_{x}^{j}\right)^{2}}\right]=10+\frac{b_{x}^{i}}{\left(b_{x}^{i}+\sum_{j \in I I, j \neq i} b_{x}^{j}\right)} B_{y} .
$$

In the symmetric Nash equilibrium,

$$
b_{x}^{i}=b_{x}, b_{y}^{i}=b_{y}, \text { for } i=1, \ldots, n,
$$

and

$$
B_{x}=n b_{x}, B_{y}=n b_{y}
$$

Thus,

$$
2\left(200-b_{y}\right) n b_{x} \frac{(n-1) b_{y}}{\left(n b_{y}\right)^{2}}=\left(10+\frac{b_{y}}{n b_{y}} n b_{x}\right),
$$

and

$$
2\left(200-b_{x}\right) n b_{y} \frac{(n-1) b_{x}}{\left(n b_{x}\right)^{2}}=\left(10+\frac{b_{x}}{n b_{x}} n b_{y}\right),
$$

or

$$
\begin{aligned}
& 2(n-1)\left(200-b_{y}\right) b_{x}=\left(10+b_{x}\right) n b_{y}, \\
& 2(n-1)\left(200-b_{x}\right) b_{y}=\left(10+b_{y}\right) n b_{x} .
\end{aligned}
$$


Subtracting (8) from (7) we obtain

$$
2(n-1) 200\left(b_{x}-b_{y}\right)=10 n\left(b_{y}-b_{x}\right) .
$$

Assuming $n>1$, equation (9) reveals that all Nash equilibria are such that $b_{x}=b_{y}$. Substitution of the latter restriction into (7) or (8) yields precisely two solutions. The first is the strict equilibrium with $b_{x}=b_{y}=0$, and allocations are equal to initial endowments. The second solution is the symmetric, full-trade Nash equilibrium, where

$$
b_{x}=b_{y}=\frac{390 n-400}{3 n-2}>0, n>1 .
$$

The latter bids imply, via (1) - (4) and using (5) the following full Nash equilibrium allocation as a function of $n$ :

$$
\begin{gathered}
\widehat{x}^{I}=10+\frac{390 n-400}{3 n-2} \\
\widehat{y}^{I}=200-\frac{390 n-400}{3 n-2} \\
\widehat{x}^{I I}=200-\frac{390 n-400}{3 n-2} \\
\widehat{y}^{I I}=10+\frac{390 n-400}{3 n-2}
\end{gathered}
$$

The parameterization used in this illustration was chosen because it yields integer values for the full Nash equilibrium allocation in the cases where $n=2$ and $n=10$ (see Table 1 below), as well as for the competitive equilibrium allocation (6). These allocations will be used in the experiment of the following section.

\section{The Experiment}

This section derives the experimental findings that motivate our theoretical model. We begin by describing our experimental design. We then discuss the main findings.

\subsection{Experimental Design}

The experiment is based on the $2 \times 2$ design of the previous Section. The treatment variables consist of: (1) the number of players in a group, 4 or 20, divided up equally between the two consumer types ( $I$ and $I I)$, so there are $n=2$ or $n=10$ of each player type, and (2) the initial endowment for each type, which was either given by $\left\{w^{I}=(10,200), w^{I I}=(200,10)\right\}$ or was set equal to the Pareto superior "full" trade Nash equilibrium levels, given in Table 1, and calculated according to (10) - (13). For comparison purposes, this table also reports the Walrasian allocation for all economies studied in this experiment using the calculation 


\begin{tabular}{ccccc}
$\begin{array}{c}\text { No. of Each } \\
\text { Player Type, } n\end{array}$ & $\begin{array}{c}\text { Group Size } \\
2 n\end{array}$ & $\begin{array}{c}\text { Full NE bids } \\
b_{x}=b_{y}\end{array}$ & $\begin{array}{c}\text { Full NE Allocation } \\
\text { Type I; Type II }\end{array}$ & $\begin{array}{c}\text { WE Allocation } \\
\text { Type I; Type II }\end{array}$ \\
\hline 2 & 4 & 95 & $(105,105) ;(105,105)$ & $(140,70) ;(70,140)$ \\
10 & 20 & 125 & $(135,75) ;(75,135)$ & $(140,70) ;(70,140)$ \\
\hline
\end{tabular}

Table 1: Equilibrium Predictions: $\mathrm{NE}=$ Nash Equilibrium, WE=Walrasian Equilibrium

\begin{tabular}{ccc} 
& \multicolumn{3}{c}{ Initial Endowment: } \\
Group Size $=4$ & $\left\{w^{I}=(10,200), w^{I I}=(200,10)\right\}$ & At Full NE Allocation \\
\cline { 2 - 3 } Group Size $=20$ & 3 Sessions (16 Sbj/Sess., 4 Groups) & 0 Sessions \\
\cline { 2 - 3 } & 3 Sessions (20 Sbj/Sess., 1 Group) & 3 Sessions (20 Sbj/Sess., 1 Group) \\
\cline { 2 - 3 }
\end{tabular}

Table 2: Experimental Design

given in (6). Notice that as the number of subjects per type increases from $n=2$ to $n=10$, the full Nash equilibrium allocation comes closer to the Walrasian competitive equilibrium allocation, an observation we will revisit later when we discuss comparative statics.

The experimental design summarized in Table 2 was chosen so that in both treatments (with $n=2$ and with $n=10$ ) the initial endowments are far away from the full Nash equilibrium prediction. In order to investigate to what degree subjects decide to trade based on rational considerations, we also studied a third treatment in which $n=10$ subjects of each type began with endowments equal to the Nash equilibrium predictions $\left\{w^{I}=(135,75), w^{I I}=(75,135)\right\}$. For each of the three cells in our experimental design, we have conducted three sessions for a total of nine sessions involving 168 subjects.

At the start of each session, subjects were randomly divided up into two equal-sized groups and assigned the roles of type $I$ or type $I I$ players. Subjects were given instructions on the objectives of both player types, but were informed that they would remain in the same role (type $I$ or type $I I$ ) in all 25 rounds of the experiment. Notice from Table 2 that in the $n=2$ treatment, we used 16 subjects per session. In these sessions, the 16 subjects were randomly divided up into four groups of 4 subjects in each of the 25 rounds played, with each group consisting of two type $I$ and two type $I I$ players. In the $n=10$ treatment, we used 20 subjects per session, ten of type $I$ and ten of type $I I$ players.

Subjects were given written instructions which were read out loud in an effort to make the instructions "common knowledge." A copy of the instructions used in one of the $n=10$ treatments is given in the Appendix; instructions for the other treatments were similar. Subjects were informed that they would participate in 25 rounds of decision-making, with each round consisting of a repetition of the exact same decision. They were instructed that there were two goods, $x$ and $y$, and they were informed of their initial endowments of these goods at the start of each round, and that these initial endowments would be the same 
at the start of every round. They were further instructed that their payoff for the round would depend on their final allocation of the two goods. They were also informed of their payoff function over final allocations: $\pi^{I}=x^{2} y$ or $\pi^{I I}=x y^{2} .^{7}$

The sequence of events in each round of the experiment was as follows. Subjects were reminded of their initial endowment of goods $x$ and $y$ and of their payoff (utility) function, all of which remained the same in every round. They were then asked to make one of three trading decisions: (1) trade good $x$ for good $y,(2)$ trade good $y$ for good $x$, or, (3) no trade. Subjects who chose option (1) or (2) (trade) were then asked how many units of good $x\left(b_{x}^{i}\right)$, or good $y\left(b_{y}^{i}\right)$, they wanted to trade for the other good ( $y$ or $x$, respectively). Trade amounts were restricted to be integers between one unit and the subject's total endowment of the good. ${ }^{8}$ Once all subjects had made their trading decisions, a computer program calculated $B_{x}=\sum_{i} b_{x}^{i}$ and $B_{y}=\sum_{i} b_{y}^{i}$ for each group and then determined each player's end-of-round allocation according the allocation rules (3) - (4). The manner in which the final allocations were chosen by the computer program was carefully explained to subjects. ${ }^{9}$

At the end of each round, all subjects were told (i) the amount they chose to trade (bid) of one good for the other (if any), (ii) the total amounts bid of goods $x$ and $y, B_{x}$ and $B_{y}$, by all members of their group (size 4 or 20) including themselves; the latter information allows them to construct the implicit prices, $p_{x}=B_{x} / B_{y}$ and $p_{y}=B_{y} / B_{x}$, (iii) the fraction of $B_{x}$ or $B_{y}$ they individually acquired from their bid (if any), (iv) their individual final allocation of goods $x$ and $y$, and finally, $(v)$ their individual payoff in points for the round and the dollar value of that point total (the conversion rate of 100,000 points $=\$ 1$ was public information). To make this information as salient as possible, we not only showed it to subjects on their computer screens but we also asked them to record all these pieces of information on individual record sheets. Once this information was provided and recorded the round was over. If the 25 th round had not yet been played, a new round would then begin.

Subjects were instructed that, at the end of the session, one round would be chosen randomly from all 25 rounds played and their dollar earnings for that round would comprise part of their earnings for the session. In addition, subjects were awarded a $\$ 5$ show-up payment. Total earnings averaged $\$ 17.28$ per subject in the three sessions where $n=2$, and $\$ 18.42$ per subject in the six sessions where $n=10$. Each session lasted about 90 minutes. Subjects were recruited from the undergraduate population at the University of Pittsburgh. No

\footnotetext{
${ }^{7}$ To aid subjects in calculating these payoffs, they were given tables displaying payoffs for type $I$ and type $I I$ players as a function of the final allocations of $x$ and $y$ for a large set of final allocations; this payoff table included the payoffs from not trading and from a wide variety of other final allocations including the trade Nash equilibrium allocation (see the instructions in the Appendix for the payoff tables shown to subjects).

${ }^{8}$ Notice that while choices were limited to just one type of trade (or no trade), we did not restrict the choice of good that either player type was allowed to trade, and no trade of either good was always a choice option.

${ }^{9}$ Before playing, subjects had to answer a number of quiz questions that tested their understanding of the experimental design, the trading rules, the final-allocation market mechanism and their understanding of the payoff table. The reader is referred to the experimental instructions, provided in the Appendix, for further details.
} 
subject participated in more than one session. Next, we turn to a description of our experimental results.

\subsection{Experimental Findings}

We begin by considering trading decisions, "end-of-round" or "final" allocations, and payoff efficiency across the three treatments of our experimental design. Specifically, we report (1) the average frequency with which each player type chose "No Trade," (2) the average amount of each good bid by each player type (among those players choosing to trade), (3) the average, final allocation for each player type, and finally, as a measure of efficiency, (4) the average payoff earned by each player type as a percentage of the full trade Nash equilibrium (Full NE) payoff.

To avoid possible learning effects (for now), we calculate four statistics for each player type using data from the last 5 rounds of each session (we will consider behavior over all 25 rounds and individual behavior later in this section). These aggregate statistics are reported in Tables 3-4, where average amounts bid ("Avg. Bid"), and average final allocations ("Final Alloc."), are represented as pairs in the format (amount of good $x$, amount of good $y$ ).

\begin{tabular}{|c|c|c|c|c|c|c|c|c|c|}
\hline \multirow[b]{2}{*}{ Session } & \multirow[b]{2}{*}{$n=$} & \multicolumn{4}{|c|}{ Type I, $w^{I}=(10,200)$} & \multicolumn{4}{|c|}{ Type II, $w^{I I}=(200,10)$} \\
\hline & & $\begin{array}{l}\% \text { No } \\
\text { Trade }\end{array}$ & $\begin{array}{l}\text { Avg. } \\
\text { Bid }\end{array}$ & $\begin{array}{l}\text { Final } \\
\text { Alloc. }\end{array}$ & $\begin{array}{l}\text { Pay. Eff. } \\
\% \text { Full NE }\end{array}$ & $\begin{array}{l}\% \text { No } \\
\text { Trade }\end{array}$ & $\begin{array}{l}\text { Avg. } \\
\text { Bid }\end{array}$ & $\begin{array}{l}\text { Final } \\
\text { Alloc. }\end{array}$ & $\begin{array}{l}\text { Pay. Eff. } \\
\% \text { Full NE }\end{array}$ \\
\hline 1 & 2 & 0.00 & $(0,95)$ & $(91,105)$ & 0.727 & 0.00 & $(81,0)$ & $(119,105)$ & 1.152 \\
\hline 2 & 2 & 0.00 & $(0,83)$ & $(115,117)$ & 1.264 & 0.00 & $(105,0)$ & $(95,93)$ & 0.737 \\
\hline 3 & 2 & 0.00 & $(0,103)$ & $(121,97)$ & 1.194 & 0.00 & $(111,0)$ & $(89,113)$ & 0.924 \\
\hline Avg. 1-3 & 2 & 0.00 & $(0,94)$ & $(109,106)$ & 1.062 & 0.00 & $(99,0)$ & $(101,104)$ & 0.937 \\
\hline Full NE & 2 & 0.00 & $(0,95)$ & $(105,105)$ & 1.000 & 0.00 & $(95,0)$ & $(105,105)$ & 1.000 \\
\hline WE & - & - & $(0,130)$ & $(140,70)$ & 1.185 & - & $(130,0)$ & $(70,140)$ & 1.185 \\
\hline$\overline{1}$ & 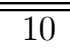 & 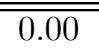 & $\overline{(0,130)}$ & $\overline{(2(129,70)}$ & 0.833 & 0.00 & $\overline{(1119,0)}$ & $\overline{(281,140)}$ & $\overline{1.111}$ \\
\hline 2 & 10 & 0.00 & $(0,113)$ & $(124,87)$ & 0.933 & 0.00 & $(114,0)$ & $(86,123)$ & 0.948 \\
\hline 3 & 10 & 0.00 & $(0,126)$ & $(140,74)$ & 1.013 & 0.00 & $(130,0)$ & $(70,136)$ & 0.902 \\
\hline Avg.1-3 & 10 & 0.00 & $(0,123)$ & $(131,77)$ & 0.926 & 0.00 & $(121,0)$ & $(79,133)$ & 0.987 \\
\hline Full NE & 10 & 0.00 & $(0,125)$ & $(135,75)$ & 1.000 & 0.00 & $(125,0)$ & $(75,135)$ & 1.000 \\
\hline WE & - & - & $(0,130)$ & $(140,70)$ & 1.004 & - & $(130.0)$ & $(70,140)$ & 1.004 \\
\hline
\end{tabular}

Table 3: Averages by Player Type I, II, from the Last Five rounds of Sessions where $w^{I}=(10,200)$, $w^{I I}=(200,10)$

Let us first consider the results for the $n=2$ and $n=10$ treatments when subjects start out with $w^{I}=(10,200)$ and $w^{I I}=(200,10)$ as reported in Table 3. The results in both treatments are striking: all subjects are choosing to engage in trade $(\%$ No Trade $=0.0)$, so subjects have clearly chosen to move away from the strict, autarkic Nash equilibrium. Further, as a first test of the subjects' understanding of the game, we observe that type $I$ subjects are choosing to bid good $y$ for good $x$, as evidenced by the 0 in the first element of their bid pairs, and likewise, type $I I$ subjects are choosing to bid good $x$ for good $y$, 
as evidenced by the 0 in the second element of their bid pairs (and not the opposite type of trades). Such bidding behavior was not imposed on subjects but rather follows from the objective of maximizing one's type-specific payoff function. That is, subjects nearly always offered to bid for the good with the higher marginal payoff for their type, even though they were free to bid for either type of good, or not to bid at all. More importantly, subjects in these treatments bid so as to achieve final allocations that are very close to the full Nash equilibrium (Full NE) by the final rounds of all sessions. Both the average amounts bid and the final end-of-round allocations are very close to these full NE predictions in both the $n=2$ and $n=10$ treatments. Indeed, we also see that subject are achieving approximately $100 \%$ of the payoffs they could have earned had all played according to the full Nash equilibrium; in some instances certain player types are doing slightly better, due to less than complete coordination on the NE and the inefficiency of that equilibrium relative to the Walrasian equilibrium. Notice further that, consistent with theoretical predictions, most of these averages lie below the Walrasian equilibrium allocation (WE) predictions. Perhaps most importantly, there is strong evidence for the comparative static prediction of greater trade volume (bid amounts) as the size of each type increases from 2 to 10. Using the three session-level averages for the bids (of good $y$ for good $x$ ) for type $I$ players or the bids (of good $x$ for good $y$ ) for type $I I$ players, a non-parametric, Mann-Whitney test confirms that we can reject the null hypothesis of no difference in bid amounts between the $n=2$ and $n=10$ treatments in favor of the alternative hypothesis that bids by both player types are greater when $n=10$ than when $n=2$ ( $p=0.05$ for both tests $)$.

This is powerful evidence that, as the number of agents in the economy increases; i.e., as the economy becomes larger, strategic considerations diminish in importance, as the full NE allocation gradually approximates that of the WE. This finding stands in some contrast to experimental findings using the double auction mechanism. Under conditions of incomplete information, the double auction mechanism typically results in rapid convergence to competitive equilibrium, regardless of whether there are many or few agents on either side of the market. ${ }^{10}$ The fact that strategic considerations (group size) matter in a predictable and intuitive way under the market game trading rules suggests that the underlying market structure matters and that the market game mechanism should be added to the set of market institutions studied by experimentalists, especially those interested in understanding market power in a general equilibrium setting.

Next, we consider the case where groups of 20 subjects ( $n=10$ of each type) start out with endowments equal to the full NE allocation, as reported in Table 4. Here we see that, contrary to the strict, full NE prediction, a majority of subjects do choose to engage in some trade - the percentage clicking on the "no trade" button (\% No Trade) over the last five rounds of each session averages just 38\% for type $I$ and $25 \%$

\footnotetext{
${ }^{10}$ For instance, markets organized under double-auction rules generate near-competitive outcomes even in the case of a single, monopoly seller (e.g., Smith (1981)), where the seller's efforts to achieve and sustain monopoly prices are ultimately unsuccessful, or in cases where one side of the market has opportunities for pre-trade collusion (Isaac and Plott (1981)).
} 


\begin{tabular}{|c|c|c|c|c|c|c|c|c|c|}
\hline \multirow[b]{2}{*}{ Session } & \multirow[b]{2}{*}{$n=$} & \multicolumn{4}{|c|}{ Type I, $w^{I}=(135,75)$} & \multicolumn{4}{|c|}{ Type II, $w^{I I}=(75,135)$} \\
\hline & & $\begin{array}{l}\% \text { No } \\
\text { Trade }\end{array}$ & $\begin{array}{l}\text { Avg. } \\
\text { Bid }\end{array}$ & $\begin{array}{l}\text { Final } \\
\text { Alloc. }\end{array}$ & $\begin{array}{l}\text { Pay. Eff. } \\
\% \text { Full NE }\end{array}$ & $\begin{array}{l}\% \text { No } \\
\text { Trade }\end{array}$ & $\begin{array}{l}\text { Avg. } \\
\text { Bid }\end{array}$ & $\begin{array}{l}\text { Final } \\
\text { Alloc. }\end{array}$ & $\begin{array}{l}\text { Pay. Eff. } \\
\% \text { Full NE }\end{array}$ \\
\hline 1 & 10 & 0.48 & $(0,6)$ & $(141,69)$ & 1.004 & 0.30 & $(6,0)$ & $(69,141)$ & 0.988 \\
\hline 2 & 10 & 0.32 & $(0,11)$ & $(147,65)$ & 1.007 & 0.26 & $(13,0)$ & $(63,145)$ & 0.928 \\
\hline 3 & 10 & 0.34 & $(1,11)$ & $(147,65)$ & 0.996 & 0.18 & $(13,1)$ & $(63,145)$ & 0.953 \\
\hline Avg. 1-3 & 10 & 0.38 & $(0,9)$ & $(145,66)$ & 1.002 & 0.25 & $(11,0)$ & $(65,144)$ & 0.956 \\
\hline Full NE & 10 & 1.00 & $(0,0)$ & $(135,75)$ & 1.000 & 1.00 & $(0,0)$ & $(75,135)$ & 1.000 \\
\hline WE & - & - & $(0,5)$ & $(140,70)$ & 1.004 & - & $(5,0)$ & $(70,140)$ & 1.004 \\
\hline
\end{tabular}

Table 4: Averages by Player Type I, II, from the Last Five rounds of Sessions where $w^{I}=(135,75)$, $w^{I I}=(75,135)$, i.e., the Full NE allocation.

for type $I I$ players. While this represents a statistically significant increase in the frequency of subjects choosing no trade over the $n=10$ treatment where subjects did not start out at the full trade NE allocation ( $p=.05$, Mann-Whitney test), the frequency of subjects choosing no trade is still far less than the theoretical prediction of $100 \%$. We make a couple of comments about this observation. First, notice that the amounts traded are rather small. Type $I$ agents trade, on average, just 9 units of good $y$ for good $x$ while type $I I$ agents trade, on average just 11 units of good $x$ for good $y$. The alternative type of trade available to each player type averages 0 , as in the other treatments. A Mann-Whitney test using session level data confirms that trade volume (bids of good $y$ for $x$ by type $I$ players and bids of good $x$ for $y$ by type $I I$ players) is significantly less in the $n=10$ treatment where subjects start out at the full NE allocation than in the $n=10$ treatment where they do not $(p=.05)$. Second, somewhat surprisingly, these small amounts of trade move subjects very close to the Walrasian equilibrium (WE) allocation. Subjects, on average, overshoot the WE to a small degree, by acquiring a little too much of the good with the higher marginal payoff. Indeed, due to the overshooting, payoff efficiency generally lies below both the full Nash and the WE predicted levels. ${ }^{11}$ In summary, while these findings clearly violate the no-trade theoretical prediction of this treatment, the violation seems rather small. We could try to partially rationalize observed behavior by noting that the endowment is not Pareto optimal and subjects are trying to find a way to achieve a more efficient outcome. Yet, there is a continuum of efficient allocations and the power of WE, despite the fact that it does not correspond to a Nash outcome in this context, remains somewhat puzzling.

\section{[Insert Figures 1-3 here.]}

Thus far we have considered only aggregate (session-level) averages. Figures 1-3 show all individual final allocations (averaged over the final 5 rounds) using data from all sessions of each of the three treatments.

\footnotetext{
${ }^{11}$ However, we again find that we cannot reject the null hypothesis of no difference in payoff efficiency for this treatment relative to the other two treatments involving $n=2$ or 10 subjects of each type where initial endowments were far away from the full NE ( $p \geq .35$, for all pairwise comparisons using the Mann-Whitney test on session-level data).
} 
These individual allocations are situated within the Edgeworth box representing the pure exchange economy that we implemented experimentally. In Figure 1, we see that for the $n=2$ treatment, where initial endowments are $w^{I}=(10,200)$ and $w^{I I}=(200,10)$, there remains considerable dispersion in individual final allocations in the final 5 rounds, though the averages for the two player types are very close to the full NE prediction. This dispersion is attributable to the relatively greater market power subjects have in this treatment. By contrast, as Figure 2 shows, when the group size increases from 4 to 20 ( $n=10$ of each type) so that market power is greatly reduced, the dispersion in individual, average final allocations is also greatly reduced, with the averages for each type remaining very close to the full NE prediction. Finally, as Figure 3 shows, when subjects interact in groups of 20 and start out at the full NE, $w^{I}=(135,75), w^{I I}=(75,135)$, the dispersion in individual, average final allocations is even further reduced. In this case, as noted earlier, the average final allocations are closer to the WE prediction than to the full NE, an intriguing effect that remains to be explained.

[Insert Figures 4-9 here.]

In addition to considering allocations over the last 5 rounds of a session, we also examine subjects' behavior over the entire 25 rounds of each session so as to assess whether there is any evidence of trends or learning behavior over time. Figures 4-6 show time series on average, individual bids of good $x$ for good $y$ and of good $y$ for good $x$ by both player types using pooled data from all three sessions of a treatment. ${ }^{12}$ Notice that, consistent with theoretical predictions, type $I$ players quickly learn to bid only good $y$ for good $x$, and type $I I$ players quickly learn to bid only good $x$ for good $y$; the alternative types of bids (dashed lines in Figures 4-6), while available to subjects, are generally small (use the LHS scale) and converge to zero over time in all treatments. Second, notice that the amounts of good $y(x)$ bid for good $x(y)$ by types $I(I I)$ are very close to the full NE predictions after only a few rounds. Specifically, in Figure 4, where subjects interact in groups of size 4 , it is predicted that type $I(I I)$ bids 95 units of good $y(x)$ for good $x(y)$, and subjects are on average close to this prediction after 5 rounds of play. Similarly, in Figure 5 where subjects interact in groups of size 20, the prediction is for type $I(I I)$ to bid 125 units of good $y(x)$ for good $x(y)$, and this prediction is, on average, close to being met after around 10 rounds of play. Finally, in Figure 6, where subjects interact in groups of size 20, but have endowments equal to the full NE, the prediction is that all bid amounts should be zero. Here type $I(I I)$ bids of good $y(x)$ for good $x(y)$ start out averaging around 20 and decrease to an average of around 10 over the 25 rounds. Thus, there is some evidence that subjects in this treatment are learning not to bid, though it is possible that this learning process was not complete

\footnotetext{
${ }^{12}$ Note the use of a different vertical scale in all three figures: The smaller vertical scale on the LHS is for type $I(I I)$ bids of good $x(y)$ for good $y(x)$ - which are predicted to be zero - while the $10 \times$ larger scale on the RHS is for type $I(I I)$ bids of good $y(x)$ for good $x(y)$, which, in treatments where subjects' initial endowments were not equal to the full NE (Figures 4-5 only), are predicted to be strictly positive.
} 
in the time-frame allowed by our design. As discussed earlier, subjects in this treatment are very close to achieving the WE allocation, which would involve type $I(I I)$ bidding 5 units of good $y(x)$ for good $x(y)$. As mentioned before, such non-Nash bidding remains puzzling.

Figures 7-9 show time series, session-level data on the implicit price of good $x, p_{x}=B_{x} / B_{y}$ (the implicit price of good $y$, being the reciprocal, is not shown). Given the symmetric nature of our parameterization of the economy, these implicit prices should equal 1 in equilibrium. In Figure 7, which shows (average) prices for the treatment where subjects interacted in groups of size 4, we see that, initially there are large departures from the equilibrium price of 1 , but this variance in prices becomes more tightly centered around the equilibrium prediction of 1 as subjects gain experience. By contrast, Figure 8 shows that prices in the treatment where subjects interacted in groups of size 20 (and therefore, had considerably less market power), are very close to the equilibrium prediction of 1 in nearly every round, beginning with the first. Finally, Figure 9 shows prices for the treatment where subjects interacted in groups of size 20 but had initial endowments equal to the full Nash equilibrium. While prices are quite volatile in this case, they remain centered around 1. The persistent volatility in the latter case possibly arises because the equilibrium prediction is for no trade, in which case prices are not well defined. Recall, however, from Table 4, that an average of only $25 \%$ to $38 \%$ of subjects were choosing not to trade each round, leading to significant market power for the remaining, off-equilibrium speculators (who bid very small amounts)-hence the persistent volatility in Figure $9 .{ }^{13}$

Summarizing our experimental design and findings, we have implemented a simple, 2-good, 2-player version of the Shapley-Shubik (1977) strategic market game in the laboratory. To our knowledge, this is the first-ever experimental test of this widely-studied game, which provides a bridge between non-cooperative game theory and general equilibrium analysis. We have found that the autarkic (no trade) outcome, while a strict Nash equilibrium, is never observed in our sessions when subjects' initial endowments are far from the full NE allocation. Instead, subjects quickly learn to bid so as to implement individual allocations and market prices that closely approximate the full NE predictions, on average. Perhaps the most striking finding is that the size of the economy, in terms of the number of agents of each player type, matters greatly for the realized outcome. In particular, we find that when subjects interact in small groups of size 4 (2 of each type) and, thus, individually possess some market power, the NE allocation to which such groups converge is far from the competitive, WE allocation. By contrast, when subjects interact in groups of 20 (10 of each type) and, thus, individually possess comparatively less market power, the NE allocation to which groups converge is much closer to the competitive WE allocation. We consider this comparative statics result an important test for the model. As we discuss in the next Section, this finding is consistent with theoretical predictions in the context of a market game. Yet, it stands in sharp contrast to a large body of experimental work

\footnotetext{
${ }^{13}$ Notice further that (with some exceptions) in this treatment, prices typically alternate (up, down) from one round to the next. This result is due to some subjects' bidding small amounts in response to prior-round market conditions.
} 
using double oral auctions where, somewhat counter to economic intuition, the size of the market economy matters little for whether or not a competitive equilibrium is achieved; competitive equilibria in experimental implementations of these auctions are reliably achieved with very small numbers of agents on either side of the market (three or less). Finally, when subjects' initial endowments are equal to the full NE allocation, we demonstrated that there is significantly less trade. In addition, and somewhat surprisingly, the trade that does occur moves allocations in the direction of the WE allocation.

Having presented strong evidence that human subjects eschew the strict, autarkic NE in favor of the full $\mathrm{NE}$ in all cases and that, as predicted, the full NE allocation approximates the competitive WE allocation as the size of the economy (number of each player type) grows, we next turn toward providing a theoretical explanation of these findings. ${ }^{14}$

\section{The Theoretical Model}

In order to help us understand the experimental findings, our theoretical model must have two important features. First, it must be able to assist in equilibrium selection by distinguishing among strict Nash equilibria. More precisely the model must generate the prediction that autarky will be escaped and a NE with trade will be reached. Second, and more importantly, the model must be able to distinguish between NE and WE and generate the right comparative statics. In particular, consistent with our experimental findings, Nash behavior must approximate Walrasian behavior only as agents' market power declines. In what follows, we build a model that has these features. In order to encompass the first feature, we first extend existing concepts in evolutionary game theory in order to account for the possibility of "coalitional deviations." In addition, our concept must be applicable in the context of a market game-like exchange. In order to encompass the second feature, we will build on a version of a market game introduced by Postlewaite and Schmeidler (1978). Their version allows us to study properties of the full NE as the number of agents in the underlying economy becomes large. While our theoretical analysis is motivated by our experimental findings, we believe that it can be useful in other contexts in which bounded rational agents can form coalitional deviations. To this end, we first develop our concept in the context of an abstract game. Later we will apply this analysis to a market game.

\subsection{The Solution Concept}

We begin by stating two existing definitions of evolutionary stability in the context of an abstract normal form game. First, consider a single population consisting of a continuum of identical agents, and assume

\footnotetext{
${ }^{14}$ In a way, our approach reverses the typical order of inquiry in the social sciences and follows a path that is more common in the natural sciences: having designed a sequence of experiments and having observed certain regularities in experimental data, we build a theoretical model in an attempt to understand the data.
} 
that $N$ agents are selected to play a normal-form game $\Gamma=(N, S, U)$, where $S$ is the set of available (pure) strategies, and $U$ represents payoffs. The definition of an Evolutionary Stable Strategy (ESS) for $(N=2)$-player symmetric games is as follows (see Weibull, 1995):

Definition 1 A strategy $s \in \Delta$ is an ESS if, for every strategy $t \in \Delta, t \neq s$, there exists $\varepsilon_{t}>0$ such that

$$
U(s,(1-\varepsilon) s+\varepsilon t)>U(t,(1-\varepsilon) s+\varepsilon t)
$$

for all $\varepsilon \in\left(0, \varepsilon_{t}\right)$, where $\Delta$ is the set of all mixed strategies.

Next, consider any finite population of size $N$. The definition of $E S S$ for $N$-player symmetric games is as follows (see Schaffer, 1988, 1989):

Definition $2 A$ strategy $s \in S$ is an ESS if, for any strategy $t \in \Delta, t \neq s$,

$$
U(s,(t, \bar{s})) \geq U(t,(s, \bar{s}))
$$

where $(t, \bar{s})$ and $(s, \bar{s})$ denote the strategies of the other $(n-1)$ players. In particular, $(s, \bar{s})$ indicates that all other players play strategy $s$, while $(t, \bar{s})$ indicates that one player plays strategy $t$, while all other players plays.

Note that, unlike Nash equilibrium, the ESS criterion refers to relative performance. We will amend Schaffer's (1988) definition in two ways. First, we extend the definition of an ESS from one to multiple, distinct, finite populations. Second, we will require a strong version of evolutionary stability: one that requires stability against simultaneous deviations by multiple agents from different populations.

We first present the concept in the context of an example. In the next section, we will apply it to a market game. Assume that there are $K>1$ finite populations. Each population, $i$, contains $n_{i} \geq 2$ agents. Agents play an $N$-player game, $\Gamma$, where $N=n_{1}+\ldots+n_{K}$. The game is assumed to have the following symmetry property. All players from population $i$ have the same set of strategies, $X^{i}$, and the same payoff function, $U^{i}$. In other words, if two players (from the same population) play the same strategy, they will obtain the same payoffs. Hence, we can indicate the normal form game as

$$
\Gamma=(\left\{n_{1}+\ldots+n_{K}\right\} ; \underbrace{S^{1} \times \ldots \times S^{1}}_{n_{1} \text { times }} \times \ldots \times \underbrace{S^{K} \times \ldots \times S^{K}}_{n_{K} \text { times }} ;\left(U^{1} ; \ldots ; U^{K}\right)) .
$$

In what follows, we will need to consider the situation where one agent from population $i$ plays strategy $t^{i}$, while every other agent from that population plays strategy $s^{i}$. More generally, in the case where at most one agent in each population plays a strategy, $t$, which is different from the one chosen by every other agent 
in his population, the payoff of the agent from population $i$ who plays a different strategy than his peers can be written as:

$$
U^{i}\left(t^{i} ;\left(t^{1}, \overline{s^{1}}\right) ; \ldots ;\left(t^{i}, \overline{s^{i}}\right) ; \ldots ;\left(t^{K}, \overline{s^{K}}\right)\right)
$$

where, as before, $\left(t^{i}, \overline{s^{i}}\right)$ denotes that one agent from population $i$ plays $t^{i}$, while all other agents from population $i$ play $s^{i}$.

We are now ready to define our main concept.

Definition 3 A symmetric strategy profile $\bar{s}=(\underbrace{s^{1}, \ldots, s^{1}}_{n_{1}} ; \ldots \underbrace{s^{K}, \ldots, s^{K}}_{n_{K}}) \in \underbrace{S^{1} \times \ldots \times S^{1}}_{n_{1}} \times \ldots \times \underbrace{S^{K} \times \ldots \times S^{K}}_{n_{K}}$ is a Strong ESS (SESS) if, for all $i$,

$$
U^{i}\left(s^{i} ; \gamma^{1}, \ldots, \gamma^{K}\right) \geq U^{i}\left(t^{i} ; \gamma^{1}, \ldots, \gamma^{K}\right),
$$

for any strategy $t^{i} \in S^{i}, t^{i} \neq s^{i}$, and for all $\gamma^{j}$, such that $\gamma^{j}=\left(s^{j}, \overline{s^{j}}\right)$, or $\gamma^{j}=\left(t^{j}, \overline{s^{j}}\right)$.

In other words, a notable feature of the $S E S S$ is that it requires stability against up to $K$ simultaneous deviations (one per population). Clearly, this is a stronger concept than Schaffer's ESS. Thus, SESS will not exist in general. An important feature of our concept is that while it requires a symmetric outcome, it can be applied to asymmetric games. Below, we give an example of a four-player coordination-like game in which SESS uniquely selects the Pareto efficient Nash equilibrium even though there is another ESS.

Example: Suppose that there are two populations ( $I$ and $I I$ ), each consisting of two players. Each player has two strategies $(a$ and $b)$. Let $\theta_{I(I I)}$ stand for the number of $a$-players in population $I(I I)$. Payoffs are defined as follows.

$$
\begin{array}{cccc}
\frac{U_{I}\left(a, \theta_{I}, \theta_{I I}\right)}{U_{I}(a, 1,0)=0} & \frac{U_{I}\left(b, \theta_{I}, \theta_{I I}\right)}{U_{I}(b, 0,0)=2} & \frac{U_{I I}\left(a, \theta_{I}, \theta_{I I}\right)}{U_{I I}(a, 0,1)=0} & \frac{U_{I I}\left(b, \theta_{I}, \theta_{I I}\right)}{U_{I I}(b, 0,0)=2} \\
U_{I}(a, 2,0)=0 & U_{I}(b, 1,0)=2 & U_{I I}(a, 0,2)=0 & U_{I I}(b, 0,1)=2 \\
U_{I}(a, 1,1)=3 & U_{I}(b, 0,1)=1 & U_{I I}(a, 1,1)=3 & U_{I I}(b, 1,0)=1 \\
U_{I}(a, 2,1)=3 & U_{I}(b, 1,1)=1 & U_{I I}(a, 1,2)=3 & U_{I I}(b, 1,1)=1 \\
U_{I}(a, 1,2)=4 & U_{I}(b, 0,2)=0 & U_{I I}(a, 2,1)=4 & U_{I I}(b, 2,0)=0 \\
U_{I}(a, 2,2)=4 & U_{I}(b, 1,2)=0 & U_{I I}(a, 2,2)=4 & U_{I I}(b, 2,1)=0
\end{array}
$$

For example, $U_{I}(a, 1,0)=0$ means that the payoff of an $a$-player from population $I$, when all other players (one player in population $I$ and two players in population $I I$ ) play action $b$, is zero. This game obtains two symmetric strict Nash equilibria in which all agents play $a$ or all play $b$, respectively. The $a$-equilibrium is an $S E S S$. Notice, however, that the b-equilibrium is not an SESS since a coalition consisting of one agent per population (type) deviating to playing $a$ will result in a payoff of 3 for each of the two deviators (instead of 1 for the $b$-players).

Later, we shall make use of the following approximate notion of an SESS. 
Definition 4 A symmetric strategy profile $\bar{s}=(\underbrace{s^{1}, \ldots, s^{1}}_{n_{1}} ; \ldots \underbrace{s^{K}, \ldots, s^{K}}_{n_{K}}) \in \underbrace{S^{1} \times \ldots \times S^{1}}_{n_{1}} \times \ldots \times \underbrace{S^{K} \times \ldots \times S^{K}}_{n_{K}}$ is an $\epsilon$-SESS if, for all $i$,

$$
U^{i}\left(s^{i} ; \gamma^{1}, \ldots, \gamma^{K}\right) \geq U^{i}\left(t^{i} ; \gamma^{1}, \ldots, \gamma^{K}\right)-\epsilon
$$

for any $t^{i} \neq s^{i}$, and for all $\gamma^{j}$, such that $\gamma^{j}=\left(s^{j}, \overline{s^{j}}\right)$, or $\gamma^{j}=\left(t^{j}, \overline{s^{j}}\right)$.

Thus, an $\epsilon$-SESS requires that no agent can be better off by more than a small amount, $\epsilon$.

In the next two sections, we develop the general strategic market game and we then motivate and use $\epsilon-S E S S$ in these games.

\subsection{The General Market Game}

For our theoretical analysis we consider a finite, convex pure exchange economy with $L$ consumption goods. ${ }^{15}$ The economy is described by $\mathcal{E}=\left\langle I, X^{i}, w^{i}, u^{i}\right\rangle_{i \in I}$, where $I=\{1, \ldots, n K\}$ is a finite set of agents belonging to $K>1$ different populations (or types); $X^{i}=\mathbb{R}_{+}^{L}$ denotes the consumption possibility set for agent $i$; $w^{i} \in \mathbb{R}_{+}^{L}$ is the endowment vector of agent $i$; and $u^{i}: \mathbb{R}_{+}^{L} \rightarrow \mathbb{R}$ is the utility function of agent $i$. Agents belonging to the same type have identical preferences and endowments. We assume that $u^{i}$ is Lipschitz continuous, strictly increasing in all its variables, and strictly quasi-concave.

We will follow Postlewaite and Schmeidler (1978), henceforth PS, in specifying the market game corresponding to $\mathcal{E}$. An $n K$-person market game in normal form is defined as follows. For each $i \in I$, let $S^{i}=\left\{s^{i}=\left(b^{i}, q^{i}\right) \in \mathbb{R}_{+}^{L} \times \mathbb{R}_{+}^{L}: q^{i} \leq w^{i}\right\}$ be the set of strategies available to agent $i$. Given any (symmetric) $n K$-list of strategies $\left(b^{i}, q^{i}\right)_{i \in I}$, the payoff to agent $i$ is denoted by $U^{i}\left(\left(b^{1}, q^{1}\right) ; \ldots ;\left(b^{i}, q^{i}\right) ; \ldots\left(b^{n K}, q^{n K}\right)\right)$. Here, $b^{i}$ denotes the vector of bids or "goods requested" by agent $i$, measured in abstract units of account, while $q^{i}$ denotes the vector of goods offered by agent $i$. We let $U^{i}: S^{1} \times \ldots \times S^{n K} \rightarrow \mathbb{R}$ indicate the von Neumann and Morgenstern utility function of agent $i$.

Individual agents have to satisfy a balance or bankruptcy condition, which requires that the total value of an agent's bids be less than the total "receipts" from his sales of goods. More precisely, the individual balance condition is given by

$$
\sum_{l \in L} b_{l}^{i} \leq \sum_{l \in L} \frac{q_{l}^{i}}{\sum_{j \in I} q_{l}^{j}} \sum_{j \in I} b_{l}^{j}
$$

One issue is how we treat agents who violate the balance condition. This is particularly important in our case for two reasons. First, unlike PS, we will explicitly consider non-Nash states in which this constraint might be violated. Second, since agents in our model are concerned with relative performance, they might

\footnotetext{
${ }^{15}$ The reader should think of the $2 \times 2$ model studied in our experimental section as a special case of the general market game studied here.
} 
take an action that will make them worse off in absolute terms if this leads to other agents of their type becoming further worse off. This could occur, for example, if an action by a single agent led to other agents' becoming bankrupt. ${ }^{16}$ With these considerations in mind, we impose the milder condition that an agent whose total value of goods requested exceeds that of his total receipts has his bid vector "shaved" by an amount that is proportional to his overbidding. More precisely, let

$$
\alpha^{i}=\frac{\sum_{l \in L} \frac{q_{l}^{i}}{\sum_{j \in I} q_{l}^{j}} \sum_{j \in I} b_{l}^{j}}{\sum_{l \in L} b_{l}^{i}}
$$

and let

$$
\widehat{b}_{l}^{i}=\left\{\begin{array}{cc}
\alpha^{i} b_{l}^{i}, & \text { if } \sum_{l \in L} b_{l}^{i}>\sum_{l \in L} \frac{q_{l}^{i}}{\sum_{j \in I} q_{l}^{j}} \sum_{j \in I} b_{l}^{j} \\
b_{l}^{i}, & \text { otherwise. }
\end{array}\right.
$$

The resulting allocations are determined as follows. For all $i \in I$, and $l \in L$, the consumption of good $l$ by agent $i$ is given by

$$
c_{l}^{i}=w_{l}^{i}-q_{l}^{i}+\frac{\widehat{b}_{l}^{i}}{\sum_{j \in I} \widehat{b}_{l}^{j}} \sum_{j \in I} q_{l}^{j} .
$$

Note that each strategy profile $\left(\left(b^{1}, q^{1}\right) ; \ldots ;\left(b^{i}, q^{i}\right) ; \ldots\left(b^{n K}, q^{n K}\right)\right)$ uniquely determines agents' consumption $\left(\left(c_{1}^{1}, \ldots, c_{L}^{1}\right), \ldots,\left(c_{1}^{n K}, \ldots, c_{L}^{n K}\right)\right)$ using $(19)$.

A (symmetric) strategy profile $\left(\widehat{s}^{1}, \ldots, \widehat{s}^{n K}\right)$ is a Nash equilibrium if for all $i \in I$ and all $s^{i} \in S^{i}$,

$$
U^{i}\left(\widehat{s}^{1}, \ldots, \widehat{s}^{i}, \ldots \widehat{s}^{n K}\right) \geq U^{i}\left(\widehat{s}^{1}, \ldots, s^{i}, \ldots \widehat{s}^{n K}\right) .
$$

A Nash equilibrium is full if all markets are open; i.e., if for all $l \in L$,

$$
\sum_{i \in I} \widehat{b}_{l}^{i}>0 \text { and } \sum_{i \in I} \widehat{q}_{l}^{i}>0 .
$$

We shall only consider economies where a full Nash equilibrium exists, in which there is (sufficiently large) positive trade in all commodities. Proceeding as in PS, for all $l$, and for a distinguished agent $i$, we can write $B_{l}=b_{l}^{i}+B_{l}^{-i}=b_{l}^{i}+\sum_{j \in I, j \neq i} b_{l}^{j}$, and $Q_{l}=q_{l}^{i}+Q_{l}^{-i}=q_{l}^{i}+\sum_{j \in I, j \neq i} q_{l}^{j}$. Let $p_{l}=B_{l} / Q_{l}$ denote the average price of commodity $l$ (provided that the denominator of this expression is strictly positive). Define an allocation $\widehat{z}$ resulting from a full Nash equilibrium to be $\epsilon$-Walrasian if all markets are open, and there exists $\widehat{p}=\left(\widehat{p}_{1}, \ldots, \widehat{p}_{L}\right)$ such that for all $i \in I, \widehat{p} \widehat{z}^{i}=\widehat{p} w^{i}$, and

$$
\#\left\{i \in I: \forall z^{i}, u^{i}\left(z^{i}\right)>u^{i}\left(\widehat{z}^{i}\right) \Rightarrow \widehat{p} z^{i}>\widehat{p}(1-\epsilon) w^{i}\right\}>(1-\epsilon) \# I,
$$

where, as stated above, prices correspond to ratios of aggregate bids. We first state the main result of PS. It establishes the connection between full Nash equilibria of the market game and approximate Walrasian equilibria of the underlying economy.

\footnotetext{
${ }^{16}$ This possibility could arise under the PS specification since they assume that agents who violate the balance condition have all their resources confiscated.
} 
Proposition 1 (PS): For any positive numbers $\alpha, \beta$, and $\epsilon$, any allocation resulting from a full Nash equilibrium in an economy $\mathcal{E}=\left\langle I, X^{i}, w^{i}, u^{i}\right\rangle_{i \in I}$ with $w^{i}<\beta(1, \ldots 1)$ for all $i \in I, \sum_{i \in I} w^{i}>N \alpha(1, \ldots, 1)$, and $N>16 L \beta / \alpha \epsilon^{2}$ is $\epsilon$-Walrasian.

This completes the description of the market game. For a more detailed discussion of these concepts, we refer the reader to PS. Motivated by our experimental findings, henceforth we will examine the evolutionary stability of certain outcomes.

\subsection{Evolutionary Stability}

Given the description of the general market game in the previous section, we can now further rationalize our choice of the SESS concept over other evolutionary approaches. First, a market game involves a continuum of strategies. Hence the evolutionary approach of Kandori, Mailath and Rob (1993), or Young (1993a) is not directly applicable. Moreover, the structure of the market game does not allow us to discretize the strategy (bid) space ${ }^{17}$ since allocations that would result from the market game mechanism may not be consistent with that discretization. In contrast, the SESS concept naturally accommodates a continuous strategy space. Finally, unlike the previous papers, our approach incorporates coalitional deviations.

Before we analyze the market game from an evolutionary point of view, we introduce our main argument in an informal way. Notice first that no Nash equilibrium in which some markets are closed can be disturbed by a single deviating agent. This is because at least one agent on each side of the market is necessary for any trade. While the existence of such (partial) autarky Nash outcomes is plausible, this outcome was never observed in our experiment. In addition, it might be insightful to study under what conditions evolutionary forces will result in the "opening of markets," leading to a Pareto superior outcome. The fact that this requires multiple simultaneous deviations is exactly what SESS is designed to capture.

A separate, and perhaps more important, issue from whether all markets will be open is whether evolution will give rise to an efficient or, more restrictively, to a Walrasian outcome. Our experimental findings gave a qualified support to this conclusion: The Walrasian equilibrium in our experiment appeared more likely to be reached when individual market power was reduced. From a theoretical point of view, one might ask whether states that correspond to full Nash equilibria are SESS. Here, a difficulty arises. The fact that we deal with a finite game implies that each individual agent has some market power. Of course, market power vanishes as the number of agents increases. This suggests that in the case where the economy is large enough, we can expect the above question to be answered in the affirmative, but only in an approximate sense.

To see this, let us assume that the economy is at a full Nash equilibrium. Suppose that an agent switches

\footnotetext{
${ }^{17}$ See Young (1993b).
} 
to a different bid/offer. Clearly, since the previous situation was a Nash equilibrium, the deviating agent will be worse off. However, this does not imply the evolutionary stability of full Nash equilibria. The reason is as follows. Since there is a finite number of agents, the deviation will result in slightly different prices for at least some agents. While the deviator is worse off under the new prices, the other agents of his type may be even more worse off or, in other words, the deviator could be better off in relative terms. Thus, the evolutionary stability of full Nash equilibria is not automatic. A continuity argument, however, guarantees that if the economy is large enough, a deviation by a small-size coalition cannot make the deviators better off by more than an arbitrarily small amount. Hence the need for the approximate SESS concept. Thus, a full Nash equilibrium of a large enough economy, which PS have shown to be approximately Walrasian, will also be an approximate $S E S S$, provided that agents lack significant market power.

Formalizing the details of this argument is the main purpose of this section. We begin by presenting a definition of $\epsilon$-SESS in the context of a market game. Define the price for good $l$ faced by agent $i$ by $p_{l}^{i}=B_{l}^{-i} / Q_{l}^{-i}$, with the convention that $p_{l}^{i}=0$ if $B_{l}^{-i}=Q_{l}^{-i}=0$. Then,

Definition 5 A symmetric strategy profile $\bar{s}=\left(\bar{s}^{1}, \ldots, \bar{s}^{1} ; \ldots ; \bar{s}^{K}, \ldots, \bar{s}^{K}\right) \in \underbrace{S^{1} \times \ldots \times S^{1}}_{n} \times \ldots \times \underbrace{S^{K} \times \ldots \times S^{K}}_{n}$ is an $\epsilon$-SESS of the market game if, for all $i \in I$

$$
U^{i}\left(\overline{s^{i}} ; \widetilde{\mathbf{p}}^{i}\right) \geq U^{i}\left(t^{i} ; \widetilde{\widetilde{\mathbf{p}}}^{i}\right)-\epsilon
$$

for any $t^{i} \in S^{i}$, and for all $\widetilde{\mathbf{p}}^{i}$, where $\widetilde{\mathbf{p}}^{i}=\left(\widetilde{B}_{1}^{-i} / \widetilde{Q}_{1}^{-i}, \ldots, \widetilde{B}_{L}^{-i} / \widetilde{Q}_{L}^{-i}\right), \widetilde{\widetilde{\mathbf{p}}}^{i}=\left(\widetilde{\widetilde{B}}_{1}^{-i} / \widetilde{\widetilde{Q}}_{1}^{-i}, \ldots, \widetilde{\widetilde{B}}_{L}^{-i} / \widetilde{\widetilde{Q}}_{L}^{-i}\right)$ and

$$
\begin{aligned}
\widetilde{B}_{l}^{-i} & =(n-2) \bar{b}_{l}^{i}+\sum_{k=1, k \neq i}^{K}(n-1) \bar{b}_{l}^{k}+\sum_{k=1}^{K} \widetilde{b}_{l}^{k}, \\
\widetilde{Q}_{l}^{-i} & =(n-2) \bar{q}_{l}^{i}+\sum_{k=1, k \neq i}^{K}(n-1) \bar{q}_{l}^{k}+\sum_{k=1}^{K} \widetilde{q}_{l}^{k}, \\
\widetilde{\widetilde{B}}^{-i} & =\sum_{k=1}^{K}(n-1) \bar{b}_{l}^{k}+\sum_{k=1, k \neq i}^{K} \widetilde{b}_{l}^{k}, \\
\widetilde{\widetilde{Q}}^{-i} & =\sum_{k=1}^{K}(n-1) \bar{q}_{l}^{k}+\sum_{k=1, k \neq i}^{K} \widetilde{q}_{l}^{k} .
\end{aligned}
$$

The above conditions require that a deviating agent be better off by at most $\epsilon$ relative to the other agents of his type when at most one agent per population deviates. The variables $\left(\widetilde{B}^{-i}, \widetilde{Q}^{-i}\right)$ and $\left(\widetilde{\widetilde{B}}^{-i}, \widetilde{\widetilde{Q}}^{-i}\right)$ give rise to the resulting prices before and after the deviation by the distinguished agent. Throughout the paper we assume that the economy in question has a symmetric full Nash equilibrium. Let $\left(\widehat{s}^{1}, \ldots, \widehat{s}^{1} ; \ldots ; \widehat{s}^{K} \ldots, \widehat{s}^{K}\right)$ denote a symmetric full Nash equilibrium profile where $\widehat{s}^{i}=\left(\widehat{b}^{i}, \widehat{q}^{i}\right)$. Our first result below is stated 
analogously to the result in PS, but in the context of our evolutionary analysis. Let

$$
\max _{i} \widehat{q}_{l}^{i}=\lambda_{l}>0, \text { for all } l \in\{1, \ldots, L\},
$$

denote the largest equilibrium offer (per population). We have the following.

Theorem 1 Consider an economy $\mathcal{E}$ and a positive number $\epsilon>0$. Fix positive constants $\beta, \lambda$, and $\theta$ satisfying: (1) $\left(\lambda_{1}, \ldots, \lambda_{L}\right)>\lambda(1, \ldots, 1)$, (2) $w^{i}<\beta(1, \ldots, 1)$, and (3) $\theta$ is a Lipschitz constant such that

$$
2 \theta[2(1+K) \beta+(K-1)] \frac{L^{2}(K-1) K^{2} \beta^{4}}{\lambda^{4}} \frac{n^{2}}{(n-1)^{3}}<\epsilon .
$$

Then, the symmetric full Nash equilibrium profile $\left(\widehat{s}^{1}, \ldots, \widehat{s}^{1} ; \ldots ; \widehat{s}^{K} \ldots, \widehat{s}^{K}\right)$ of the market game associated with $\mathcal{E}$ is an $\epsilon$-SESS.

The proof appears in the Appendix. We briefly discuss the conditions needed for the above Theorem. The first condition requires that the full Nash equilibrium involves a strictly positive amount of trade in all markets. The second condition is also employed in PS. It assumes that individual endowments are "small." Finally, the third condition is satisfied if the number of agents belonging to each type, $n$, is sufficiently large.

The proof proceeds by deriving explicit bounds for the effects of a deviating coalition on the terms of trade. Such effects are small provided that the economy is sufficiently large. Given this fact, the proof establishes that the resulting change in consumption baskets and, thus, in utility, for the non-deviating agents is also small.

A couple of remarks are in order. First, the proof of the above Theorem uses the "large economy" assumption. This turns out to be a necessary condition for the result. This feature is consistent with our experimental findings and we consider it to be a central feature of our model as it suggests that evolutionary arguments can be used as a foundation for Walrasian equilibria only when agents lack market power. We discuss this issue further below. Next, we demonstrate two additional facts. First, outcomes in which some markets are closed are not consistent with SESS. Second, if all markets are open, only full Nash equilibrium outcomes can be consistent with SESS. We begin by studying the first assertion.

Theorem 2 Consider an economy $\mathcal{E}$ and suppose that a symmetric strategy profile $\left(s^{1}, \ldots, s^{1} ; \ldots ; s^{K} \ldots, s^{K}\right)$ is associated with an outcome where market $l$ is closed; i.e., $b_{l}^{i}=q_{l}^{i}=0$, for all $i \in I$. Then, there exists $\epsilon_{0}>0$ such that the profile $\left(s^{1}, \ldots, s^{1} ; \ldots ; s^{K} \ldots, s^{K}\right)$ is not an $\epsilon_{0}$-SESS.

The proof of this Theorem appears later in the Section. We will demonstrate that, in any state in which a market is closed, there exists a coalition of agents (one agent per type) such that if the coalition opens the market, at least one member of the coalition can always become better off after trading than any non-deviant 
agent of his type. In this sense, the proof of the Theorem is "destructive." We will describe a coalitional deviation which guarantees a higher payoff for one (but possibly not all!) of the deviating agents. Indeed, that at least one member of the deviating coalition is better off is all that is required to violate the SESS criterion. A stronger form of Theorem 2 holds for the special case of the autarky (no trade) equilibrium. Then, there exists a coalition $C$ such that, by introducing trade, coalition $C$ opens all markets and makes all of its members better off. No approximation argument is needed in that case. We state this result next.

Proposition 2 Consider an economy $\mathcal{E}$ and the strategy profile associated with no trade, $b_{l}^{i}=q_{l}^{i}=0$ for all $i \in I$ and all $l \in\{1, \ldots, L\}$. This profile is not an SESS. Moreover, there exists a deviating coalition of agents (one per population) such that each member of the coalition obtains a higher payoff than in autarky.

Proof: Denote the strategy profile associated with no trade by $(\overline{\mathbf{0}}, \ldots, \overline{\mathbf{0}})$. In the full Nash equilibrium, $\left(\widehat{s}^{1}, \ldots, \widehat{s}^{1} ; \ldots ; \widehat{s}^{K} \ldots, \widehat{s}^{K}\right)$, each agent obtains a payoff strictly higher than the corresponding payoff associated with a no-trade strategy profile; i.e.,

$$
U^{i}\left(\widehat{s}^{i} ; \widehat{\mathbf{p}}^{i}\right)>U^{i}\left(\overline{\mathbf{0}} ; \stackrel{\mathbf{p}}{ }^{i}\right)
$$

where $\grave{\mathbf{p}}^{i}=\left(\stackrel{\mathrm{p}}{1}_{1}^{i}, \ldots, \grave{\mathbf{p}}_{L}^{i}\right)=(0 / 0, \ldots, 0 / 0)$. Note that, in the symmetric full Nash equilibrium, all agents from the same population play the same strategy. Thus, agent $i$ 's consumption of good $l$ can be written as

$$
\begin{aligned}
& \widehat{c}_{l}^{i}=w_{l}^{i}-\widehat{q}_{l}^{i}+\frac{\widehat{b}_{l}^{i}}{\sum_{j \in I} \widehat{b}_{l}^{j}} \sum_{j \in I} \widehat{q}_{l}^{j} \\
& =w_{l}^{i}-\widehat{q}_{l}^{i}+\frac{\widehat{b}_{l}^{i}}{n \sum_{k=1}^{K} \widehat{b}_{l}^{k}} n \sum_{k=1}^{K} \widehat{q}_{l}^{k} \\
& =w_{l}^{i}-\widehat{q}_{l}^{i}+\frac{\widehat{b}_{l}^{i}}{\sum_{k=1}^{K} \widehat{b}_{l}^{k}} \sum_{k=1}^{K} \widehat{q}_{l}^{k} .
\end{aligned}
$$

Let us restrict attention to the no-trade strategy profile. Consider a coalition, $C$, consisting of exactly one agent per type ( $K$ agents in total), and suppose that each agent in $C$ deviates to the strategy prescribed by the full Nash equilibrium. In that case, the following strategy profile arises $\left(\widehat{s}^{1}, \overline{\mathbf{0}}, \ldots, \overline{\mathbf{0}} ; \widehat{s}^{2}, \overline{\mathbf{0}}, \ldots, \overline{\mathbf{0}} ; \widehat{s}^{K}, \overline{\mathbf{0}}, \ldots, \overline{\mathbf{0}}\right)$. Note that each deviant agent $i$ 's individual consumption of good $l$ is given by

$$
c_{l}^{i}=w_{l}^{i}-\widehat{q}_{l}^{i}+\frac{\widehat{b}_{l}^{i}}{\sum_{k=1}^{K} \widehat{b}_{l}^{k}} \sum_{k=1}^{K} \widehat{q}_{l}^{k}=\widehat{c}_{l}^{i} .
$$

Since $c_{l}^{i}=\widehat{c}_{l}^{i}$, for any $l \in\{1, \ldots, L\}$, for each deviant agent $i$, we have that $U^{i}\left(\widehat{s}^{i} ; \mathbf{p}^{i}\right)=U^{i}\left(\widehat{s}^{i} ; \widehat{\mathbf{p}}^{i}\right)$, where $\mathbf{p}^{i}=\left(p_{1}^{i}, \ldots, p_{L}^{i}\right)$ is the price vector faced by the deviant agent $i$. Therefore,

$$
U^{i}\left(\widehat{s}^{i} ; \mathbf{p}^{i}\right)=U^{i}\left(\widehat{s}^{i} ; \widehat{\mathbf{p}}^{i}\right)>U^{i}\left(\overline{\mathbf{0}} ; \dot{\mathbf{p}}^{i}\right)
$$


Hence the strategy profile associated with no trade $(\overline{\mathbf{0}}, \ldots, \overline{\mathbf{0}})$ is not an SESS.

The above Proposition is consistent with our experimental findings. It offers a strong sense in which autarky, although a strong Nash equilibrium, is not likely to be observed. ${ }^{18}$ A general version of the above Proposition is contained in Theorem 2. The proof below employs a coalitional deviation consisting of two agents who open a market that was previously inactive. The first of these agents offers his entire endowment of the good whose corresponding market was closed, in exchange for an arbitrarily small amount, $\eta>0$, of another good. This exchange does not significantly affect prices on any previously opened markets. However, it makes the second agent in the deviating coalition "significantly better off" than any non-deviant agent of his type.

Proof of Theorem 2: Consider a symmetric strategy profile $\left(s^{1}, \ldots, s^{1} ; \ldots ; s^{K} \ldots, s^{K}\right)$ which is associated with an outcome where market $l$ is closed; i.e., $b_{l}^{i}=q_{l}^{i}=0$, for all $i \in I$. Note that all agents from the same population play the same strategy. Thus, agent $i$ 's consumption of good $h$ is given by

$$
\begin{gathered}
c_{h}^{i}=w_{h}^{i}-q_{h}^{i}+\frac{b_{h}^{i}}{\sum_{j \in I} b_{h}^{j}} \sum_{j \in I} q_{h}^{j} \\
=w_{h}^{i}-q_{h}^{i}+\frac{b_{h}^{i}}{n \sum_{k=1}^{K} b_{h}^{k}} n \sum_{k=1}^{K} q_{h}^{k} \\
=w_{h}^{i}-q_{h}^{i}+\frac{b_{h}^{i}}{\sum_{k=1}^{K} b_{h}^{k}} \sum_{k=1}^{K} q_{h}^{k} .
\end{gathered}
$$

Since each strategy profile uniquely determines players' consumption through (19), we have that

$$
U^{i}\left(s^{i} ; s^{-i}\right)=u^{i}\left(c_{1}^{i}, \ldots, c_{L}^{i}\right)
$$

Choose an arbitrary agent, say of type $i$, with $w_{l}^{i}>0$. If all other markets (in addition to that of good $l$ ) are closed, the result follows directly from Proposition 2. Thus, assume that there exists good $h$ and type $j$ such that $b_{h}^{j}>\eta>0$. Now, consider a coalition $C=\{i, j\}$ and suppose that $C$ deviates by opening the market for good $l$ through adopting

$$
\widetilde{q}_{l}^{i}=w_{l}^{i}, \widetilde{b}_{l}^{j}=\eta
$$

in exchange for

$$
\widetilde{b}_{h}^{i}=b_{h}^{i}+\eta, \widetilde{b}_{h}^{j}=b_{h}^{j}-\eta .
$$

\footnotetext{
${ }^{18}$ For instance, in our $2 \times 2$ experimental economy, where endowments for the two types were $w^{I}=(10,200)$ and $w^{I I}=$ $(200,10)$, the utility in autarky is $u_{a}^{I}=u_{a}^{I I}=10^{2} \cdot 200$. A deviation by one agent of each type to bid away, say, 100 units of the good that gives them the lower marginal utility, yields payoffs to each deviating agent of $u_{d}^{I}=u_{d}^{I I}=110^{2} \cdot 100>u_{a}^{I}=u_{a}^{I I}$.
} 
Note that the prices for all goods except good $l$ are not affected by the deviation of coalition $C$. Thus, each non-deviant agent of type $j$ has the same payoff as before. However, the deviating agent, $j$, obtains a strictly higher payoff than any non-deviant agent of his type. More precisely, denote

$$
\epsilon_{0}=\frac{2}{3}\left[u^{j}\left(c_{1}^{j}, \ldots, c_{l-1}^{j}, \widetilde{c}_{l}^{j}, c_{l+1}^{j}, \ldots, c_{L}^{i}\right)-u^{j}\left(c_{1}^{j}, \ldots, c_{l-1}^{j}, c_{l}^{j}, c_{l+1}^{j}, \ldots, c_{L}^{i}\right)\right]>0 .
$$

Let $\widetilde{c}_{l}^{j}$ denote the resulting consumption of good $l$ by the deviant agent $j$. We then have

$$
\begin{gathered}
u^{j}\left(c_{1}^{j}, \ldots, c_{l-1}^{j}, \widetilde{c}_{l}^{j}, c_{l+1}^{j}, \ldots, c_{h-1}^{j}, \widetilde{c}_{h}^{j}, c_{h+1}^{j}, \ldots, c_{L}^{i}\right)-u^{j}\left(c_{1}^{j}, \ldots, c_{l-1}^{j}, c_{l}^{j}, c_{l+1}^{j}, \ldots, c_{L}^{i}\right) \\
=\left(u^{j}\left(c_{1}^{j}, \ldots, c_{l-1}^{j}, \widetilde{c}_{l}^{j}, c_{l+1}^{j}, \ldots, c_{h-1}^{j}, \widetilde{c}_{h}^{j}, c_{h+1}^{j}, \ldots, c_{L}^{i}\right)-u^{j}\left(c_{1}^{j}, \ldots, c_{l-1}^{j}, \widetilde{c}_{l}^{j}, c_{l+1}^{j}, \ldots, c_{L}^{i}\right)\right) \\
\quad+\left(u^{j}\left(c_{1}^{j}, \ldots, c_{l-1}^{j}, \widetilde{c}_{l}^{j}, c_{l+1}^{j}, \ldots, c_{L}^{i}\right)-u^{j}\left(c_{1}^{j}, \ldots, c_{l-1}^{j}, c_{l}^{j}, c_{l+1}^{j}, \ldots, c_{L}^{i}\right)\right) \\
>\frac{3}{2} \epsilon_{0}- \\
\left|u^{j}\left(c_{1}^{j}, \ldots, c_{l-1}^{j}, \widetilde{c}_{l}^{j}, c_{l+1}^{j}, \ldots, c_{h-1}^{j}, \widetilde{c}_{h}^{j}, c_{h+1}^{j}, \ldots, c_{L}^{i}\right)-u^{j}\left(c_{1}^{j}, \ldots, c_{l-1}^{j}, \widetilde{c}_{l}^{j}, c_{l+1}^{j}, \ldots, c_{L}^{i}\right)\right| .
\end{gathered}
$$

The function $u^{j}\left(c_{1}^{j}, \ldots, c_{L}^{i}\right)$ is continuous in all its arguments. Therefore, for all $\widetilde{c}_{h}^{j}$ such that $\left|\widetilde{c}_{h}^{j}-c_{h}^{j}\right|=$ $\eta<\delta_{1}\left(\epsilon_{0}\right)$, we have

$$
\left|u^{j}\left(c_{1}^{j}, \ldots, c_{l-1}^{j}, \widetilde{c}_{l}^{j}, c_{l+1}^{j}, \ldots, c_{h-1}^{j}, \widetilde{c}_{h}^{j}, c_{h+1}^{j}, \ldots, c_{L}^{i}\right)-u^{j}\left(c_{1}^{j}, \ldots, c_{l-1}^{j}, \widetilde{c}_{l}^{j}, c_{l+1}^{j}, \ldots, c_{L}^{i}\right)\right|<\frac{\epsilon_{0}}{2} .
$$

Thus, the strategy profile associated with an outcome where at least one of the markets is not open is not an $\epsilon_{0}-S E S S$ for $\eta<\delta_{1}\left(\epsilon_{0}\right)$.

Next, we demonstrate another necessary condition for evolutionary stability. The corresponding allocation must be resulting from a symmetric full Nash equilibrium. Like before, for any strategy profile $\left(t^{1}, \ldots, t^{K}\right)$, and for all goods $j$ for which the corresponding market is open, let $\max _{i} q_{l}^{i}=\lambda_{l}>0$ denote the largest offer (per population) in the given state. Since the definition of $\epsilon$-SESS involves symmetry, it is sufficient to consider only symmetric profiles. We have the following.

Theorem 3 Fix an economy $\mathcal{E}$ and assume that all markets are open. Let $\left(t^{1}, \ldots, t^{1} ; \ldots ; t^{K}, \ldots, t^{K}\right)$ be a symmetric non-Nash equilibrium profile of the underlying market game. Then, there exists $\epsilon_{0}>0$ such that for any positive constants $\beta, \lambda$, and $\theta$ satisfying: (1) $\left(\lambda_{1}, \ldots, \lambda_{L}\right)>\lambda(1, \ldots, 1)$, (2) $w^{i}<\beta(1, \ldots, 1)$, and (3) $\theta$ is the Lipschitz constant such that

$$
2 \theta \frac{\beta^{4}}{\lambda^{4}} L K^{2}(\lambda+(L K+L) \beta) \frac{n^{3}}{(n-1)^{4}}<\epsilon_{0},
$$

the profile $\left(t^{1}, \ldots, t^{K}\right)$ is not an $\epsilon_{0}$-SESS. 
The proof appears in the Appendix. Summarizing our findings, Theorems 1-3 demonstrate that for any $\epsilon>0$, if the economy $\mathcal{E}$ is "large," any symmetric full Nash equilibrium profile of the market game associated with $\mathcal{E}$ is an $\epsilon$-SESS. Proposition 1, from PS, demonstrates that any allocation resulting from a full Nash equilibrium in a large enough economy is approximately Walrasian. Hence, SESS provides support for approximately Walrasian outcomes in sufficiently large economies. These results are consistent with the experimental findings of the previous Section. In this sense, they provide plausible theoretical explanations for the observed behavior in our rudimentary $2 \times 2$ experiments.

As we mentioned before, the above results will not hold in general if the economy is populated by a small number of agents. In that case, by having a non-negligible effect on prices, an agent deviating from the full Nash equilibrium allocation may be able to make himself better off relative to the other agents of his type. Therefore, full Nash equilibria may not correspond to $\epsilon$-SESS if agents have significant market power. While this observation is consistent with the traditionally held view that competitive outcomes arise when individual agents are of insignificant size, it is in contrast to findings in Vega-Redondo (1997), where a competitive outcome is evolutionary stable in the context of a Cournot oligopoly model where agents have significant market power.

\section{Discussion}

Experimental results on double auctions (DA) give remarkably strong support for Walrasian equilibrium (WE) outcomes. This is true even when there is a small number of agents in both sides of the market. Vernon Smith (1982) referred to this property as a "scientific mystery." ${ }^{19}$ This raises the important question of whether Walrasian price formation crucially depends on the choice of market institution. Is this support particular to the way a DA "aggregates" agents' actions and information, or is it a property of WE itself? In the second case, the apparent emergence of WE should be shared by a variety of market mechanisms, in addition to the DA. This question can be studied in the context of several models of price formation such as the partial equilibrium setups of Cournot and Bertrand. However, little experimental work has been done to investigate the performance of different "general equilibrium" market structures.

Market games as in Shapley and Shubik (1977) offer such mechanisms in that they involve the general equilibrium properties of the Walrasian paradigm while, at the same time, they are fully specified noncooperative games. These two features make them particularly suitable for studying whether Walrasian prices will emerge under different specifications of the underlying economic environment; i.e., the agents'

\footnotetext{
${ }^{19}$ Smith (1982, p. 945) recognized that "many economists express surprise, if not discomfort, with the evidence [that convergence to competitive equilibrium obtains with small numbers of competing agents]." He adds that "the idea that a competitive equilibrium is an ideal frictionless state not likely to be approached in any observable market — and certainly not without a large number of agents with its assumed concomitant "price taking" behavior — is a deeply ingrained belief based on untested theory going back to Cournot. Since Cournot's theory does not specify an institution, it is unclear in what context the theory is supposed to have relevance."
} 
preferences, endowments, etc.

The role of private information in Smith's scientific mystery is not fully understood. Since they completely abstract from private information frictions, market games offer a rudimentary setup that allows us to isolate issues related to the emergence of WE from the effects of private information. More precisely, rational behavior in a market game requires a standard Nash equilibrium best response as opposed to the BayesianNash equilibrium biding strategies required in DAs, in which subjects must form consistent beliefs about other subjects' values, etc. As Friedman (1993) observes, the formation of such belief/action assessments is a rather demanding task. In contrast, the only relevant variable in a market game is the price, as defined by the ratio of the aggregate bids. As the above discussion suggests, since subjects are playing a "simpler" game, their performance should be expected to be at least as good as that exhibited in the more complex DA setup.

Within the DA framework, the k-DA or "call market ${ }^{20 "}$-a simultaneous-move, sealed-bid version of the DA- is the closest analog to the strategic market game studied here, in the sense that prices are determined in a centralized fashion and there is no possibility of re-contracting. While both the k-DA and market games depart from the asynchronous trading of the (continuous) DA, they are considerably easier to analyze. Using the k-DA, Satterthwaite and Williams find theoretical support for WE when the economy is large. In addition, they perform simulations that offer some support for WE even when the number of agents is small. An experimental test of the k-DA by Kagel and Vogt (1993) found that as the number of traders increases, efficiency also increases but at a rate that is slower than the Bayesian-Nash equilibrium predicts. In related experimental work, Cason and Friedman (1997) studied k-DAs in which they varied the value of k, a parameter used to determine the single market clearing price. They report that bidders do not shade their bids a much as the Bayesian-Nash equilibrium predicts; i.e., bidders do not fully exploit their market power, even after considerable experience with the mechanism. They further observe that market prices are not very responsive to changes in the price rule $(\mathrm{k})$ and that market efficiency is lower than the Bayesian-Nash equilibrium prediction.

One feature of the $k$-DA is that it is subject to severe multiplicity of equilibrium. Although less severe, multiplicity is also present in strategic market games. More precisely, among other partial autarky outcomes, such games always obtain a strict equilibrium that involves no trade. One can, thus, ask whether agents in a laboratory setup will "learn" to open markets when this would lead to a Pareto superior outcome. While obviously interesting, the issue of opening new markets has not been sufficiently explored in an experimental setup.

Even if one expects that subjects find it easier to play "rationally" in a market game than in a DA,

\footnotetext{
${ }^{20}$ See, for example, Satterthwaite and Williams (1993).
} 
an interesting issue arises as to which outcome will be eventually selected. In all finite games there is a discrepancy between the Nash equilibrium with trade and the Walrasian outcome. Which of the two will the subjects' actions converge to? On the one hand, Nash equilibrium is the outcome consistent with rationality. Alternatively, since the Nash equilibrium is socially inefficient, one might also expect that subjects will find their way to a socially efficient outcome, perhaps through bids that implement Walrasian prices. The question of whether a Nash or a Walrasian outcome will be selected becomes particularly interesting when it is studied as a function of the number of subjects in the game.

The above question is important since, unlike the Walrasian outcome, even the most efficient Nash outcome involves an inefficiency due to market power. Satterthwaite and Williams (2002) study this inefficiency in a wide class of mechanisms and conclude that the "worst-case" inefficiency converges to zero at the fastest possible rate in a $k$-DA. Postlewaite and Schmeidler (1978) established the connection between the most efficient Nash equilibrium of a "large enough" market game and approximate Walrasian equilibria of the underlying economy. Cason and Friedman (1997) report experimental findings that are closer to the Bayesian-Nash equilibrium than the Walrasian equilibrium. The performance of market games in that regard has not been investigated experimentally and our paper offers a first attempt in this direction.

Throughout the paper we required stability against coalitions consisting of $K$ agents (one per population). One could ask whether our results would be different if we required stability against any coalitions of size $K$ (possibly several per population). Indeed, our results would hold under this more general specification (we adopted the more restrictive notion for notational convenience). This is because any outcome that does not satisfy our notion of stability would not satisfy the more general notion. In addition, full Nash equilibria will satisfy the more general notion since, provided that the economy is sufficiently large, there is no coalition consisting of $K$ agents that will have an appreciable effect on the price vector. Thus, the approximate evolutionary stability of full Nash equilibria will remain intact under the more general specification. ${ }^{21}$

Peck and Shell (1990) and Ghosal and Morelli (2004) study variations of market games in which competitive outcomes prevail even when the number of traders is small. It would be interesting to study whether our evolutionary story can be embedded in their setups. Finally, an important extension of our analysis concerns the relation between our static SESS concept and the asymptotically stable points of a suitably defined dynamic system describing the learning process. This extension is left to future research. Future work might also include studying economies with many goods, more general preferences, and multiple Walrasian equilibria.

\footnotetext{
${ }^{21}$ Clearly, the two notions will not be equivalent in all games. Our concept could be used in biological examples in which simultaneous mutations, say by a male and a female, might be needed in order to increase population fitness. See Noldeke and Samuelson (2003) and references therein for related examples in biology.
} 


\section{References}

[1] Alchian, A.A. (1950): "Uncertainty, Evolution, and Economic Theory," Journal of Political Economy $58,211-222$.

[2] Arrow, K.J., and L. Hurwicz (1958): "On the Stability of the Competitive Equilibrium, I," Econometrica $26(4), 522-552$.

[3] Cason T.N., and D. Friedman (1997): "Price Formation in Single Call Markets," Econometrica, 65, 311-345.

[4] Dubey P., and M. Shubik (1977): "A Closed Economic System with Production and Exchange Modelled as a Game of Strategy," Journal of Mathematical Economics 4, 1-35.

[5] Dubey P., and M. Shubik (1978): "A Theory of Money and Financial Institutions. The Non-Cooperative Equilibria of a Closed Trading Economy with Market Supply and Bidding Strategies," Journal of Economic Theory 17(1), 1-20.

[6] Friedman, D. (1993): "The Double Auction Market Institution: A Survey." In D. Friedman and J. Rust, Eds., The Double Auction Market: Institutions, Theories, and Evidence. Proceedings Volume XIV, Santa Fe Institute Studies in the Sciences of Complexity. Cambridge, MA: Perseus Publishing, $3-25$.

[7] Ghosal S., and M. Morelli (2004): "Retrading in Market Games," Journal of Economic Theory 115, 151-181.

[8] Isaac, R.M., and C.R. Plott (1981): "The Opportunity for Conspiracy in Restraint of Trade: An Experimental Study," Journal of Economic Behavior and Organization 2, 1-30.

[9] Kagel, J., and W. Vogt (1993): "Buyer's Bid Double Auctions: Preliminary Experimental results." In D. Friedman and J. Rust, Eds., The Double Auction Market: Institutions, Theories, and Evidence. Proceedings Volume XIV, Santa Fe Institute Studies in the Sciences of Complexity. Cambridge, MA: Perseus Publishing, 285-305.

[10] Kandori, M., G. Mailath and R. Rob (1993): "Learning, Mutation and Long-Run Equilibria in Games," Econometrica 61, 29-56.

[11] Mas-Colell, A. (1982): "The Cournotian Foundations of Walrasian Equilibrium Theory: An Exposition of Recent Theory." In W. Hildenbrand, Ed., Advances in Economic Theory. Econometric Society Publication No. 1. Cambridge University Press. 
[12] Noldeke G., and L. Samuelson (2003): "Strategic Choice Handicaps When Females Seek High Male Net Viability," Journal of Theoretical Biology 221, 53-59.

[13] Peck J., and K. Shell (1990): "Liquid Markets and Competition," Games and Economic Behavior 2(4), 362-377.

[14] Postlewaite, A., and D. Schmeidler (1978): "Approximate Efficiency of non-Walrasian Nash Equilibria," Econometrica 46, 127-135.

[15] Samuelson, L. (1997): Evolutionary Games and Equilibrium Selection. MIT Press.

[16] Satterthwaite, M., and S. Williams (1993): "The Bayesian Theory of the k-Double Auction." In D. Friedman and J. Rust, Eds., The Double Auction Market: Institutions, Theories, and Evidence. Proceedings Volume XIV, Santa Fe Institute Studies in the Sciences of Complexity. Cambridge, MA: Perseus Publishing, 99-123.

[17] Satterthwaite, M., and S. Williams (2002): "The Optimality of a Simple Market Mechanism," Econometrica, 70, 1841-1863.

[18] Schaffer, M. (1988): "Evolutionary Stable Strategies for a Finite Population and a Variable Contest Size," Journal of Theoretical Biology 132, 469-478.

[19] Schaffer, M. (1989): “Are Profit-Maximizers the Best Survivors?" Journal of Economic Behavior and Organization 12, 29-45.

[20] Shapley, L.S. (1977): "Noncooperative General Exchange," in Theory and Measurement of Economic Externalities. S. A. Y. Lin., Eds, Academic Press, New York.

[21] Shapley, L.S., and M. Shubik (1977): "Trade Using one Commodity as a Means of Payment," Journal of Political Economy 85(5), 937-968.

[22] Shubik, M. (1972): "Commodity Money, Oligopoly, Credit, and Bankruptcy in a General Equilibrium Model," Western Economic Journal 10, 24-38.

[23] Smith, V.L. (1981): "An Empirical Study of Decentralized Institutions of Monopoly Restraint," in: G. Horwich and J.P. Quirk, Eds., Essays in Contemporary Fields of Economics, West Lafayette: Purdue University Press, 83-106.

[24] Smith, V.L. (1982): "Microeconomic Systems as an Experimental Science" American Economic Review 72, 923-955. 
[25] Vega-Redondo, F. (1996): Evolution, Games, and Economic Behaviour, New York : Oxford University Press

[26] Vega-Redondo, F. (1997): "The Evolution of Walrasian Behavior," Econometrica 65(2), 375-384.

[27] Weibull, J. (1995): Evolutionary Game Theory. MIT Press.

[28] Young, P. H. (1993a): "The Evolution of Conventions," Econometrica 61, 57-84.

[29] Young, P. H. (1993b): “An Evolutionary Model of Bargaining," Journal of Economic Theory 59, 145-168. 


\section{Appendix}

Proof of Theorem 1: Fix an economy $\mathcal{E}$ and let $\epsilon>0$ be given. Suppose that $\left(\widehat{s}^{1}, \ldots, \widehat{s}^{1} ; \ldots ; \widehat{s}^{K} \ldots, \widehat{s}^{K}\right)$ is a symmetric full Nash equilibrium profile. Each strategy profile uniquely determines players' consumption through (19). Thus, in a symmetric full Nash equilibrium, agent $i$ 's consumption of good $l$ is given by

$$
\begin{aligned}
& \widehat{c}_{l}^{i}=w_{l}^{i}-\widehat{q}_{l}^{i}+\frac{\widehat{b}_{l}^{i}}{\sum_{j \in I} \widehat{b}_{l}^{j}} \sum_{j \in I} \widehat{q}_{l}^{j} \\
& =w_{l}^{i}-\widehat{q}_{l}^{i}+\frac{\widehat{b}_{l}^{i}}{n \sum_{k=1}^{K} \widehat{b}_{l}^{k}} n \sum_{k=1}^{K} \widehat{q}_{l}^{k} \\
& =w_{l}^{i}-\widehat{q}_{l}^{i}+\frac{\widehat{b}_{l}^{i}}{\sum_{k=1}^{K} \widehat{b}_{l}^{k}} \sum_{k=1}^{K} \widehat{q}_{l}^{k} .
\end{aligned}
$$

Since all markets are open, $\frac{\sum_{k=1}^{K} \widehat{q}_{l}^{k}}{\sum_{k=1}^{K} \vec{b}_{l}^{k}}>0$. Note that any unilateral deviation, $t^{i} \neq \widehat{s}^{i}$, from the full Nash equilibrium by an agent of type $i$ does not improve his payoff; i.e.,

$$
U^{i}\left(\widehat{s}^{i} ; \gamma^{i}\right)-U^{i}\left(t^{i} ; \gamma^{i}\right)=U^{i}\left(\widehat{s}^{i} ; \widehat{s}^{-i}\right)-U^{i}\left(t^{i} ; \widehat{s}^{-i}\right) \geq 0
$$

where $\gamma^{j}=\left(\widehat{s}^{j}, \widehat{s}^{j}\right)$ for all $j \neq i$. Consider a coalition of agents, $C \neq \emptyset$, consisting of at most one agent per type, who deviates from the full Nash equilibrium. Denote by $t^{i}$ a deviation by an agent of type $i$ and let $\widetilde{\widehat{c}}_{l}\left(\widetilde{g}_{l}^{i}\right)$ denote the resulting individual consumption of good $l$ by a non-deviant (deviant) agent of type $i$. Then, for any $t^{i} \neq \widehat{s}^{i}$, and for all $\gamma^{j}$ such that $\gamma^{j}=\left(\widehat{s}^{j}, \widehat{s}^{j}\right)$ or $\gamma^{j}=\left(t^{j}, \widehat{s}^{j}\right)$, we have

$$
\begin{gathered}
U^{i}\left(\widehat{s}^{i} ; \gamma^{1}, \ldots, \gamma^{K}\right)-U^{i}\left(t^{i} ; \gamma^{1}, \ldots, \gamma^{K}\right) \\
=U^{i}\left(\widehat{s}^{i} ; \gamma^{1}, \ldots, \gamma^{K}\right)-U^{i}\left(\widehat{s}^{i} ; \gamma^{i}\right) \\
\quad+U^{i}\left(\widehat{s}^{i} ; \gamma^{i}\right)-U^{i}\left(t^{i} ; \gamma^{i}\right) \\
+U^{i}\left(t^{i} ; \gamma^{i}\right)-U^{i}\left(t^{i} ; \gamma^{1}, \ldots, \gamma^{K}\right) \geq \\
-\left|U^{i}\left(\widehat{s}^{i} ; \gamma^{1}, \ldots, \gamma^{K}\right)-U^{i}\left(\widehat{s}^{i} ; \gamma^{i}\right)\right|-\left|U^{i}\left(t^{i} ; \gamma^{i}\right)-U^{i}\left(t^{i} ; \gamma^{1}, \ldots, \gamma^{K}\right)\right| .
\end{gathered}
$$

Next, we consider the differences $\left|U^{i}\left(\widehat{s}^{i} ; \gamma^{1}, \ldots, \gamma^{K}\right)-U^{i}\left(\widehat{s}^{i} ; \gamma^{i}\right)\right|$ and $\left|U^{i}\left(t^{i} ; \gamma^{i}\right)-U^{i}\left(t^{i} ; \gamma^{1}, \ldots, \gamma^{K}\right)\right|$. From (19) note that

$$
\left|U^{i}\left(\widehat{s}^{i} ; \gamma^{1}, \ldots, \gamma^{K}\right)-U^{i}\left(\widehat{s}^{i} ; \gamma^{i}\right)\right|=\left|u^{i}\left(\widetilde{\widehat{c}}_{1}^{i}, \ldots, \widetilde{\widehat{c}}_{L}^{i}\right)-u^{i}\left(d_{1}^{i}, \ldots, d_{L}^{i}\right)\right|,
$$

where $d_{l}^{i}$ denotes the individual consumption of good $l$ by a non-deviant agent of type $i$ when only one agent of type $i$ deviates from the symmetric Nash equilibrium. Likewise,

$$
\left|U^{i}\left(t^{i} ; \gamma^{i}\right)-U^{i}\left(t^{i} ; \gamma^{1}, \ldots, \gamma^{K}\right)\right|=\left|u^{i}\left(\widetilde{\widetilde{g}}_{1}^{i}, \ldots, \widetilde{\widetilde{g}}_{L}^{i}\right)-u^{i}\left(\widetilde{g}_{1}^{i}, \ldots, \widetilde{g}_{L}^{i}\right)\right|,
$$


where $\widetilde{\widetilde{g}}_{l}^{i}$ denotes the individual consumption of good $l$ by a deviant agent of type $i$ when only one agent of type $i$ (the deviator himself) deviates from the symmetric Nash equilibrium.

The function $u^{i}\left(c_{1}^{i}, \ldots, c_{L}^{i}\right)$ is Lipschitz continuous. Therefore, we have

$$
\left|u^{i}\left(\widetilde{\widehat{c}}_{1}^{i}, \ldots, \widetilde{\widehat{c}}_{L}^{i}\right)-u^{i}\left(d_{1}^{i}, \ldots, d_{L}^{i}\right)\right| \leq \theta \max _{l}\left|\widetilde{\widehat{c}}_{l}^{i}-d_{l}^{i}\right|,
$$

and

$$
\left|u^{i}\left(\widetilde{\widetilde{g}}_{1}^{i}, \ldots, \widetilde{\widetilde{g}}_{L}^{i}\right)-u^{i}\left(\widetilde{g}_{1}^{i}, \ldots, \widetilde{g}_{L}^{i}\right)\right| \leq \theta \max _{l}\left|\widetilde{\widetilde{g}}_{l}^{i}-\widetilde{g}_{l}^{i}\right|
$$

Hence, from (29)-(32),

$$
\begin{gathered}
U^{i}\left(\widehat{s}^{i} ; \gamma^{1}, \ldots, \gamma^{K}\right)-U^{i}\left(t^{i} ; \gamma^{1}, \ldots, \gamma^{K}\right) \geq \\
-\theta\left(\max _{l}\left|\widetilde{\widehat{c}}_{l}^{i}-d_{l}^{i}\right|+\max _{l}\left|\widetilde{\widetilde{g}}_{l}^{i}-\widetilde{g}_{l}^{i}\right|\right) .
\end{gathered}
$$

Next, we need to estimate the value of $\max _{l}\left|\widetilde{\widehat{c}}_{l}^{i}-d_{l}^{i}\right|$ and $\max _{l}\left|\widetilde{\widetilde{g}}_{l}^{i}-\widetilde{g}_{l}^{i}\right|$. We have:

$$
\begin{gathered}
\max _{l}\left|\widehat{\widehat{c}}_{l}^{i}-d_{l}^{i}\right|=\mid w_{l}^{i}-\widehat{q}_{l}^{i}+\frac{\widehat{b}_{l}^{i}}{\sum_{k=1}^{K} \widetilde{b}_{l}^{k}+(n-1) \sum_{k=1}^{K} \widehat{b}_{l}^{k}}\left[\sum_{k=1}^{K} \widetilde{q}_{l}^{k}+(n-1) \sum_{k=1}^{K} \widehat{q}_{l}^{k}\right]-\left(w_{l}^{i}-\widehat{q}_{l}^{i}\right) \\
\quad-\left(\frac{\widehat{b}_{l}^{i}}{\widetilde{b}_{l}^{i}+\sum_{k \neq i} \widehat{b}_{l}^{k}+(n-1) \sum_{k=1}^{K} \widehat{b}_{l}^{k}}\left[\widetilde{q}_{l}^{i}+\sum_{k \neq i, k=1}^{K} \widehat{q}_{l}^{k}+(n-1) \sum_{k=1}^{K} \widehat{q}_{l}^{k}\right]\right) \mid \\
=\widehat{b}_{l}^{i}\left|\frac{\sum_{k \neq i, k=1}^{K} \widetilde{q}_{l}^{k}+\left(\widetilde{q}_{l}^{i}+(n-1) \sum_{k=1}^{K} \widehat{q}_{l}^{k}\right)}{\sum_{k \neq i, k=1}^{K} \widetilde{b}_{l}^{k}+\left(\widetilde{b}_{l}^{i}+(n-1) \sum_{k=1}^{K} \widehat{b}_{l}^{k}\right)}-\frac{\sum_{k \neq i, k=1}^{K} \widehat{q}_{l}^{k}+\left(\widetilde{q}_{l}^{i}+(n-1) \sum_{k=1}^{K} \widehat{q}_{l}^{k}\right)}{\sum_{k \neq i, k=1}^{K} \widehat{b}_{l}^{k}+\left(\widetilde{b}_{l}^{i}+(n-1) \sum_{k=1}^{K} \widehat{b}_{l}^{k}\right)}\right| .
\end{gathered}
$$

Denote

$$
Q=\left(\widetilde{q}_{l}^{i}+(n-1) \sum_{k=1}^{K} \widehat{q}_{l}^{k}\right)
$$

and

$$
B=\left(\widetilde{b}_{l}^{i}+(n-1) \sum_{k=1}^{K} \widehat{b}_{l}^{k}\right)
$$

Then,

$$
\begin{gathered}
\left|\frac{\sum_{k \neq i, k=1}^{K} \widetilde{q}_{l}^{k}+\left(\widetilde{q}_{l}^{i}+(n-1) \sum_{k=1}^{K} \widehat{q}_{l}^{k}\right)}{\sum_{k \neq i, k=1}^{K} \widetilde{b}_{l}^{k}+\left(\widetilde{b}_{l}^{i}+(n-1) \sum_{k=1}^{K} \widehat{b}_{l}^{k}\right)}-\frac{\sum_{k \neq i, k=1}^{K} \widehat{q}_{l}^{k}+\left(\widetilde{q}_{l}^{i}+(n-1) \sum_{k=1}^{K} \widehat{q}_{l}^{k}\right)}{\sum_{k \neq i, k=1}^{K} \widehat{b}_{l}^{k}+\left(\widetilde{b}_{l}^{i}+(n-1) \sum_{k=1}^{K} \widehat{b}_{l}^{k}\right)}\right| \\
=\left|\frac{\sum_{k \neq i, k=1}^{K} \widetilde{q}_{l}^{k}+Q}{\sum_{k \neq i, k=1}^{K} \widetilde{b}_{l}^{k}+B}-\frac{\sum_{k \neq i, k=1}^{K} \widehat{q}_{l}^{k}+Q}{\sum_{k \neq i, k=1}^{K} \widehat{b}_{l}^{k}+B}\right| \\
=\left|\frac{\left(\sum_{k \neq i, k=1}^{K} \widetilde{q}_{l}^{k}+Q\right)\left(\sum_{k \neq i, k=1}^{K} \widehat{b}_{l}^{k}+B\right)-\left(\sum_{k \neq i, k=1}^{K} \widehat{q}_{l}^{k}+Q\right)\left(\sum_{k \neq i, k=1}^{K} \widetilde{b}_{l}^{k}+B\right)}{\left(\sum_{k \neq i, k=1}^{K} \widetilde{b}_{l}^{k}+B\right)\left(\sum_{k \neq i, k=1}^{K} \widehat{b}_{l}^{k}+B\right)}\right|
\end{gathered}
$$




$$
\begin{aligned}
&= \mid \frac{B \sum_{k \neq i, k=1}^{K} \widetilde{q}_{l}^{k}+Q \sum_{k \neq i, k=1}^{K} \widehat{b}_{l}^{k}+\left(\sum_{k \neq i, k=1}^{K} \widetilde{q}_{l}^{k}\right)\left(\sum_{k \neq i, k=1}^{K} \widehat{b}_{l}^{k}\right)}{\left(\sum_{k \neq i, k=1}^{K} \widetilde{b}_{l}^{k}+B\right)\left(\sum_{k \neq i, k=1}^{K} \widehat{b}_{l}^{k}+B\right)} \\
&-\frac{B \sum_{k \neq i, k=1}^{K} \widehat{q}_{l}^{k}-Q \sum_{k \neq i, k=1}^{K} \widetilde{b}_{l}^{k}-\left(\sum_{k \neq i, k=1}^{K} \widehat{q}_{l}^{k}\right)\left(\sum_{k \neq i, k=1}^{K} \widetilde{b}_{l}^{k}\right) \mid}{\left(\sum_{k \neq i, k=1}^{K} \widetilde{b}_{l}^{k}+B\right)\left(\sum_{k \neq i, k=1}^{K} \widehat{b}_{l}^{k}+B\right)} \mid \\
& \leq \frac{B\left|\sum_{k \neq i, k=1}^{K} \widetilde{q}_{l}^{k}-\sum_{k \neq i, k=1}^{K} \widehat{q}_{l}^{k}\right|}{\left(\sum_{k \neq i, k=1}^{K} \widetilde{b}_{l}^{k}+B\right)\left(\sum_{k \neq i, k=1}^{K} \widehat{b}_{l}^{k}+B\right)}+\frac{Q\left|\sum_{k \neq i, k=1}^{K} \widehat{b}_{l}^{k}-\sum_{k \neq i, k=1}^{K} \widetilde{b}_{l}^{k}\right|}{\left(\sum_{k \neq i, k=1}^{K} \widetilde{b}_{l}^{k}+B\right)\left(\sum_{k \neq i, k=1}^{K} \widehat{b}_{l}^{k}+B\right)} \\
&+\frac{\left|\left(\sum_{k \neq i, k=1}^{K} \widetilde{q}_{l}^{k}\right)\left(\sum_{k \neq i, k=1}^{K} \widehat{b}_{l}^{k}\right)-\left(\sum_{k \neq i, k=1}^{K} \widehat{q}_{l}^{k}\right)\left(\sum_{k \neq i, k=1}^{K} \widetilde{b}_{l}^{k}\right)\right|}{\left(\sum_{k \neq i, k=1}^{K} \widetilde{b}_{l}^{k}+B\right)\left(\sum_{k \neq i, k=1}^{K} \widehat{b}_{l}^{k}+B\right)} .
\end{aligned}
$$

We now proceed by estimating the above expression. Using (6), we have

$$
b_{l}^{i} \leq \sum_{l \in L} \frac{q_{l}^{i}}{\sum_{j \in I} q_{l}^{j}} \sum_{j \in I} b_{l}^{j} \leq L \frac{\beta}{(n-1) \lambda} n K \beta,
$$

or, summing up,

$$
B=\left(\widetilde{b}_{l}^{i}+(n-1) \sum_{k=1}^{K} \widehat{b}_{l}^{k}\right) \leq(1+(n-1) K) L K \frac{\beta^{2}}{\lambda} \frac{n}{(n-1)} .
$$

Using assumption (2) of the Theorem, we also have

$$
Q=\left(\widetilde{q}_{l}^{i}+(n-1) \sum_{k=1}^{K} \widehat{q}_{l}^{k}\right) \leq(1+(n-1) K) \beta,
$$

and

$$
\left|\sum_{k \neq i, k=1}^{K} \widetilde{q}_{l}^{k}-\sum_{k \neq i, k=1}^{K} \widehat{q}_{l}^{k}\right| \leq(K-1) \beta
$$

Inequality (36) leads to

$$
\left|\sum_{k \neq i, k=1}^{K} \widehat{b}_{l}^{k}-\sum_{k \neq i, k=1}^{K} \widetilde{b}_{l}^{k}\right| \leq(K-1) K L \frac{\beta^{2}}{\lambda} \frac{n}{(n-1)} .
$$

Finally, assumption (2) and inequality (36) give

$$
\begin{gathered}
\left|\left(\sum_{k \neq i, k=1}^{K} \widetilde{q}_{l}^{k}\right)\left(\sum_{k \neq i, k=1}^{K} \widehat{b}_{l}^{k}\right)-\left(\sum_{k \neq i, k=1}^{K} \widehat{q}_{l}^{k}\right)\left(\sum_{k \neq i, k=1}^{K} \widetilde{b}_{l}^{k}\right)\right| \\
\leq L K(K-1)^{2} \frac{\beta^{3}}{\lambda} \frac{n}{(n-1)} .
\end{gathered}
$$

Note that assumption (1) implies the following inequalities:

$$
B=\left(\widetilde{b}_{l}^{i}+(n-1) \sum_{k=1}^{K} \widehat{b}_{l}^{k}\right) \geq(n-1) \lambda
$$


and

$$
\left(\sum_{k \neq i, k=1}^{K} \widetilde{b}_{l}^{k}+B\right)\left(\sum_{k \neq i, k=1}^{K} \widehat{b}_{l}^{k}+B\right) \geq(n-1)^{2} \lambda^{2} .
$$

Thus, we obtain

$$
\begin{gathered}
\frac{B\left|\sum_{k \neq i, k=1}^{K} \widetilde{q}_{l}^{k}-\sum_{k \neq i, k=1}^{K} \widehat{q}_{l}^{k}\right|}{\left(\sum_{k \neq i, k=1}^{K} \widetilde{b}_{l}^{k}+B\right)\left(\sum_{k \neq i, k=1}^{K} \widehat{b}_{l}^{k}+B\right)}+\frac{Q\left|\sum_{k \neq i, k=1}^{K} \widehat{b}_{l}^{k}-\sum_{k \neq i, k=1}^{K} \widetilde{b}_{l}^{k}\right|}{\left(\sum_{k \neq i, k=1}^{K} \widetilde{b}_{l}^{k}+B\right)\left(\sum_{k \neq i, k=1}^{K} \widehat{b}_{l}^{k}+B\right)} \\
+\frac{\left|\left(\sum_{k \neq i, k=1}^{K} \widetilde{q}_{l}^{k}\right)\left(\sum_{k \neq i, k=1}^{K} \widehat{b}_{l}^{k}\right)-\left(\sum_{k \neq i, k=1}^{K} \widehat{q}_{l}^{k}\right)\left(\sum_{k \neq i, k=1}^{K} \widetilde{b}_{l}^{k}\right)\right|}{\left(\sum_{k \neq i, k=1}^{K} \widetilde{b}_{l}^{k}+B\right)\left(\sum_{k \neq i, k=1}^{K} \widehat{b}_{l}^{k}+B\right)} \leq \\
\frac{(1+(n-1) K) L K \frac{\beta^{2}}{\lambda} \frac{n}{(n-1)}(K-1) \beta+(1+(n-1) K) \beta(K-1) K L \frac{\beta^{2}}{\lambda} \frac{n}{(n-1)}}{(n-1)^{2} \lambda^{2}} \\
+\frac{L K(K-1)^{2} \frac{\beta^{3}}{\lambda} \frac{n}{(n-1)}}{(n-1)^{2} \lambda^{2}}=\frac{L(K-1) K \beta^{2}}{\lambda^{3}}\left|\frac{[2(1+(n-1) K) \beta+(K-1)] n}{(n-1)^{3}}\right| .
\end{gathered}
$$

Now, we finally have

$$
\begin{gathered}
\max _{l}\left|\widetilde{\widehat{c}}_{l}^{i}-d_{l}^{i}\right|< \\
\frac{L^{2}(K-1) K^{2} \beta^{4}}{\lambda^{4}}\left|\frac{[2(1+(n-1) K) \beta+(K-1)] n^{2}}{(n-1)^{4}}\right|< \\
\frac{L^{2}(K-1) K^{2} \beta^{4}}{\lambda^{4}}\left|\frac{[2(1+K) \beta+(K-1)] n^{2}}{(n-1)^{3}}\right|<\frac{\epsilon}{2 \theta},
\end{gathered}
$$

where the last inequality follows from assumption (3). Similarly, we can obtain

$$
\max _{l}\left|\widetilde{\widetilde{g}}_{l}^{i}-\widetilde{g}_{l}^{i}\right|<\frac{\epsilon}{2 \theta} .
$$

From (42), (43), and (33) we finally obtain

$$
U^{i}\left(\widehat{s}^{i} ; \gamma^{1}, \ldots, \gamma^{K}\right)-U^{i}\left(t^{i} ; \gamma^{1}, \ldots, \gamma^{K}\right) \geq-\epsilon
$$

In other words, a full Nash equilibrium profile is an $\epsilon-S E S S$.

Proof of Theorem 3: Consider any symmetric Non-Nash strategy profile $\left(t^{1}, \ldots, t^{1} ; \ldots ; t^{K}, \ldots, t^{K}\right)$ such that all markets are open. Then, there exists an agent, say from population $i$, such that by deviating to a different strategy, say $\widetilde{s}^{i}$, he obtains a strictly higher absolute payoff; i.e.,

$$
U^{i}\left(\widetilde{s}^{i} ; t^{-i}\right)>U^{i}\left(t^{i} ; t^{-i}\right) .
$$


To complete the proof, we need to demonstrate that this also results in the payoffs to non-deviant agents changing only by a small amount. To this end, let

$$
\epsilon_{0}=\frac{2}{3}\left[U^{i}\left(\widetilde{s}^{i} ; t^{-i}\right)-U^{i}\left(t^{i} ; t^{-i}\right)\right]>0
$$

Let $\widetilde{g}_{l}^{i}\left(c_{l}^{i}\right)$ denote the resulting individual consumption of good $l$ by a non-deviant (deviant) agent of type $i$. Then

$$
\begin{gathered}
U^{i}\left(\widetilde{s}^{i} ; \gamma^{i}\right)-U^{i}\left(t^{i} ; \gamma^{i}\right) \\
=\left(U^{i}\left(\widetilde{s}^{i} ; t^{-i}\right)-U^{i}\left(t^{i} ; t^{-i}\right)\right)+\left(U^{i}\left(t^{i} ; t^{-i}\right)-U^{i}\left(t^{i} ; \gamma^{i}\right)\right) \\
>\frac{3}{2} \epsilon_{0}-\left|U^{i}\left(t^{i} ; t^{-i}\right)-U^{i}\left(t^{i} ; \gamma^{i}\right)\right|,
\end{gathered}
$$

where $\gamma^{j}=\left(t^{j}, \overline{t^{j}}\right)$ for all $j \neq i$.

We now consider the difference $\left|U^{i}\left(t^{i} ; t^{-i}\right)-U^{i}\left(t^{i} ; \gamma^{i}\right)\right|$. Note that, from (19),

$$
\left|U^{i}\left(t^{i} ; t^{-i}\right)-U^{i}\left(t^{i} ; \gamma^{i}\right)\right|=\left|u^{i}\left(\widetilde{g}_{1}^{i}, \ldots, \widetilde{g}_{L}^{i}\right)-u^{i}\left(\widetilde{\widetilde{g}}_{1}^{i}, \ldots, \widetilde{\widetilde{g}}_{L}^{i}\right)\right|,
$$

where $\widetilde{\widetilde{g}}_{l}^{i}$ denotes the individual consumption of good $l$ by a non-deviant agent of type $i$ when only one agent of type $i$ deviates from the symmetric strategy profile $\left(t^{1}, \ldots, t^{1} ; \ldots ; t^{K}, \ldots, t^{K}\right)$.

The function $u^{i}\left(\widetilde{g}_{1}^{i}, \ldots, \widetilde{g}_{L}^{i}\right)$ is Lipschitz continuous. Therefore, we have

$$
\left|u^{i}\left(\widetilde{g}_{1}^{i}, \ldots, \widetilde{g}_{L}^{i}\right)-u^{i}\left(\widetilde{\widetilde{g}}_{1}^{i}, \ldots, \widetilde{\widetilde{g}}_{L}^{i}\right)\right| \leq \theta \max _{l}\left|\widetilde{g}_{l}^{i}-\widetilde{\widetilde{g}}_{l}^{i}\right| .
$$

Like in the proof of Theorem 1, we now need to estimate the value of $\max _{l}\left|\widetilde{g}_{l}^{i}-\widetilde{\widetilde{g}}_{l}^{i}\right|$. We have

$$
\begin{gathered}
\max _{l}\left|\widetilde{g}_{l}^{i}-\widetilde{\widetilde{g}}_{l}^{i}\right|=\mid w_{l}^{i}-q_{l}^{i}+\frac{b_{l}^{i}}{n \sum_{k=1}^{K} b_{l}^{k}}\left[n \sum_{k=1}^{K} q_{l}^{k}\right] \\
-\left(w_{l}^{i}-q_{l}^{i}+\frac{b_{l}^{i}}{\widetilde{b}_{l}^{i}+\sum_{k \neq i, k=1}^{K} b_{l}^{k}+(n-1) \sum_{k=1}^{K} b_{l}^{k}}\left[\widetilde{q}_{l}^{i}+\sum_{k \neq i, k=1}^{K} q_{l}^{k}+(n-1) \sum_{k=1}^{K} q_{l}^{k}\right]\right) \mid \\
=b_{l}^{i}\left|\frac{q_{l}^{i}+\left(\sum_{k \neq i, k=1}^{K} q_{l}^{k}+(n-1) \sum_{k=1}^{K} q_{l}^{k}\right)}{b_{l}^{i}+\left(\sum_{k \neq i, k=1}^{K} b_{l}^{k}+(n-1) \sum_{k=1}^{K} b_{l}^{k}\right)}-\frac{\widetilde{q}_{l}^{i}+\left(\sum_{k \neq i, k=1}^{K} q_{l}^{k}+(n-1) \sum_{k=1}^{K} q_{l}^{k}\right)}{\widetilde{b}_{l}^{i}+\left(\sum_{k \neq i, k=1}^{K} b_{l}^{k}+(n-1) \sum_{k=1}^{K} b_{l}^{k}\right)}\right| .
\end{gathered}
$$

Again, denote

$$
Q=\left(\sum_{k \neq i, k=1}^{K} q_{l}^{k}+(n-1) \sum_{k=1}^{K} q_{l}^{k}\right)
$$

and

$$
B=\left(\sum_{k \neq i, k=1}^{K} b_{l}^{k}+(n-1) \sum_{k=1}^{K} b_{l}^{k}\right)
$$


Then,

$$
\begin{gathered}
\left|\frac{q_{l}^{i}+\left(\sum_{k \neq i, k=1}^{K} q_{l}^{k}+(n-1) \sum_{k=1}^{K} q_{l}^{k}\right)}{b_{l}^{i}+\left(\sum_{k \neq i, k=1}^{K} b_{l}^{k}+(n-1) \sum_{k=1}^{K} b_{l}^{k}\right)}-\frac{\widetilde{q}_{l}^{i}+\left(\sum_{k \neq i, k=1}^{K} q_{l}^{k}+(n-1) \sum_{k=1}^{K} q_{l}^{k}\right)}{\widetilde{b}_{l}^{i}+\left(\sum_{k \neq i, k=1}^{K} b_{l}^{k}+(n-1) \sum_{k=1}^{K} b_{l}^{k}\right)}\right| \\
=\left|\frac{q_{l}^{i}+Q}{b_{l}^{i}+B}-\frac{\widetilde{q}_{l}^{i}+Q}{\widetilde{b}_{l}^{i}+B}\right|=\left|\frac{\left(q_{l}^{i}+Q\right)\left(\widetilde{b}_{l}^{i}+B\right)-\left(\widetilde{q}_{l}^{i}+Q\right)\left(b_{l}^{i}+B\right)}{\left(b_{l}^{i}+B\right)\left(\widetilde{b}_{l}^{i}+B\right)}\right| \\
=\left|\frac{q_{l}^{i} B+\widetilde{b}_{l}^{i} Q+q_{l}^{\widetilde{b}} \widetilde{b}_{l}^{i}-\widetilde{q}_{l}^{i} B-b_{l}^{i} Q-\widetilde{q}_{l}^{i} b_{l}^{i}}{\left(b_{l}^{i}+B\right)\left(\widetilde{b}_{l}^{i}+B\right)}\right|=\left|\frac{\left(q_{l}^{i}-\widetilde{q}_{l}^{i}\right) B+\left(\widetilde{b}_{l}^{i}-b_{l}^{i}\right) Q+\left(q_{l}^{\widetilde{b}} \widetilde{b}_{l}^{i}-\widetilde{q}_{l}^{i} b_{l}^{i}\right)}{\left(b_{l}^{i}+B\right)\left(\widetilde{b}_{l}^{i}+B\right)}\right| \\
\leq \frac{\left|q_{l}^{i}-\widetilde{q}_{l}^{i}\right| B+\left|\widetilde{b}_{l}^{i}-b_{l}^{i}\right| Q+\left|q_{l}^{i} \widetilde{b}_{l}^{i}-\widetilde{q}_{l}^{i} b_{l}^{i}\right|}{\left(b_{l}^{i}+B\right)\left(\widetilde{b}_{l}^{i}+B\right)} .
\end{gathered}
$$

Note that from assumption (2) we have:

$$
\begin{gathered}
B=\left(\sum_{k \neq i, k=1}^{K} b_{l}^{k}+(n-1) \sum_{k=1}^{K} b_{l}^{k}\right) \leq(n K-1) \beta, \\
Q=\left(\sum_{k \neq i, k=1}^{K} q_{l}^{k}+(n-1) \sum_{k=1}^{K} q_{l}^{k}\right) \leq(n K-1) \beta, \\
\left|q_{l}^{i}-\widetilde{q}_{l}^{i}\right| \leq \beta \\
\left|\widetilde{b}_{l}^{i}-b_{l}^{i}\right| \leq L \frac{\beta}{(n-1) \lambda} n K \beta,
\end{gathered}
$$

and

$$
\left|q_{l}^{i} \widetilde{b}_{l}^{i}-\widetilde{q}_{l}^{i} b_{l}^{i}\right| \leq L \frac{\beta}{(n-1) \lambda} n K \beta^{2} .
$$

In addition, from assumption (1),

$$
B=\left(\sum_{k \neq i, k=1}^{K} b_{l}^{k}+(n-1) \sum_{k=1}^{K} b_{l}^{k}\right) \geq(n-1) \lambda,
$$

and

$$
\left(b_{l}^{i}+B\right)\left(\widetilde{b}_{l}^{i}+B\right) \geq(n-1)^{2} \lambda^{2} .
$$

Inequalities (52) - (58) imply that

$$
\frac{\left|q_{l}^{i}-\widetilde{q}_{l}^{i}\right| B+\left|\widetilde{b}_{l}^{i}-b_{l}^{i}\right| Q+\left|q_{l}^{\widetilde{b}} \widetilde{b}_{l}^{i}-\widetilde{q}_{l}^{i} b_{l}^{i}\right|}{\left(b_{l}^{i}+B\right)\left(\widetilde{b}_{l}^{i}+B\right)} \leq
$$




$$
\begin{gathered}
\left|\frac{\beta(n K-1) \beta+L \frac{\beta}{(n-1) \lambda} n K(n K-1) \beta^{2}+L \frac{\beta}{(n-1) \lambda} n K \beta^{2}}{(n-1)^{2} \lambda^{2}}\right| \leq \\
\frac{\beta^{2}}{\lambda^{3}}\left|\frac{\lambda(n K-1)(n-1)+L K n(n K-1) \beta+L \beta n K}{(n-1)^{3}}\right| .
\end{gathered}
$$

From assumption (2), we have

$$
b_{l}^{i} \leq L \frac{\beta}{(n-1) \lambda} n K \beta .
$$

Hence, we obtain

$$
\begin{gathered}
\max _{l}\left|\widetilde{g}_{l}^{i}-\widetilde{\widetilde{g}}_{l}^{i}\right| \leq \\
\frac{\beta^{2}}{\lambda^{3}}\left|\frac{\lambda(n K-1)(n-1)+L K n(n K-1) \beta+L \beta n K}{(n-1)^{3}}\right| L \frac{\beta}{(n-1) \lambda} n K \beta \\
<\frac{\beta^{4}}{\lambda^{4}} L K\left|\frac{\lambda K n^{2}+L K^{2} n^{2} \beta+L K \beta n}{(n-1)^{3}}\right| \frac{n}{(n-1)} \leq \\
\frac{\beta^{4}}{\lambda^{4}} L K^{2}(\lambda+(L K+L) \beta) \frac{n^{3}}{(n-1)^{4}} \leq \frac{\epsilon_{0}}{2 \theta},
\end{gathered}
$$

where the last inequality follows from assumption (3).

Finally, from (48), (49), and (60) we obtain

$$
\begin{gathered}
U^{i}\left(\widetilde{s}^{i} ; \gamma^{i}\right)-U^{i}\left(t^{i} ; \gamma^{i}\right)> \\
\frac{3}{2} \epsilon_{0}-\left|U^{i}\left(t^{i} ; t^{-i}\right)-U^{i}\left(t^{i} ; \gamma^{i}\right)\right| \geq \frac{3}{2} \epsilon_{0}-\frac{1}{2} \epsilon_{0} \geq \epsilon_{0} .
\end{gathered}
$$

Therefore, the profile $\left(t^{1}, \ldots, t^{K}\right)$ is not an $\epsilon_{0}$-SESS. 


\section{Appendix: Instructions Used in the Experiment}

Here we provide the instructions used in treatment (1) involving groups of 4 players, and treatment (2) involving groups of 20 players. In both of these treatments, Type I (1)

players begin with an $(X, Y)$ endowment of $(10,200)$ while Type II $(2)$ players begin with an $(\mathrm{X}, \mathrm{Y})$ endowment of $(200,10)$. Instructions for treatment (3), where groups of 20 players start at the full Nash equilibrium are omitted as they are identical to the instructions for treatment (2) except that the initial endowments are changed to $(135,75)$ for Type 1 and $(75,135)$ for Type 2 (the full NE values). Note further that all three treatments make use of the same payoff tables for Types 1 and 2, so these payoff tables only appear once in this appendix. 
[Treatment (1) involving groups of 4 players].

\section{Instructions}

Welcome to this experiment in economic decision-making. Funds for this experimental study have been provided by the University of Pittsburgh. Please read these instructions carefully as they explain how you earn money from the decisions that you make. There is NO TALKING for the duration of this experiment. If you have a question, please raise your hand.

Today's session involves 16 participants. At the start of the session, all participants will be divided up equally into one of two types, Type 1 or Type 2 . The types differ only in their preferences for the two types of goods, Good X and Good Y, as will be explained below. Your type will be shown on your computer screen and will not change for the duration of the experiment.

\section{Sequence of Play in Each Period}

In today's experiment you will participate in 25 periods of decision-making. At the start of each period, you will be randomly and anonymously matched with three other participants: one of the same type as you and two of the opposite type. All possible matchings involving two Type 1 and two Type 2 players are equally likely. You will never know the identity of any member of your group nor will they know your identity even after the session is over.

You will start the period with an initial "endowment” of Good X and of Good Y that will be shown to you on your computer screen. This initial endowment depends on your type and since your type never changes, your initial endowment will be the same at the start of each period. After you are randomly matched with three other participants, all four of you must simultaneously make a choice. Your choices are: 1) Trade Good X for Good Y, 2) Trade Good Y for Good X or 3) No Trade. Click on the radio button next to your choice and then click the Submit button. You can change your choice any time prior to clicking the Submit button.

If you choose options 1 or 2: Trade Good X for Good Y or Trade Good Y for Good X, then an input box will appear. In this box, you must type in the quantity of the good you wish to trade for the other good. Quantity amounts are restricted to be integers (no decimals, please). The minimum quantity you can offer to trade is 1 unit and the maximum quantity you can offer to trade is your entire endowment of that good (X or $\mathrm{Y}$ ).

If you choose option 3: No Trade, you will not participate in any trade of Good X or Y for the other good and will end the period with your initial endowment of these two goods.

\section{Your End-Of-Period Allocation}

Your end-of-period-allocation is the amount of good $\mathrm{X}$ and good $\mathrm{Y}$ you have at the end of the period. This end-of-period allocation determines your payoff in points for the round as explained below. 
If you chose No Trade, your end-of-period allocation is the SAME as your initial endowment of Good X and Good Y.

If you chose to Trade Good X for Good Y, or to Trade Good Y for Good X, then your end-of-period allocation depends on the amount you offered to trade and the amounts and goods the other three members of your group chose to trade.

Let $\Sigma \mathrm{x}$ be the total amount of good $\mathrm{x}$ offered for trade by all members of your group including you and let $\Sigma y$ be the total amount of good $\mathrm{Y}$ offered for trade by all members of your group including you.

If you chose to Trade Good X for Good Y and you offered x units of Good X, then your end of period allocation is determined as follows:

End of period allocation of good X = Initial amount of Good X - x (amount offered in trade).

End of period allocation of good $\mathrm{Y}=$ Initial amount of Good $\mathrm{Y}+(\mathrm{x} / \Sigma \mathrm{x}) \times \Sigma \mathrm{y}$.

If you chose to Trade Good Y for Good X and offered y units of Good Y, then your end of period allocation is determined as follows:

End of period allocation of good $\mathrm{X}=$ Initial amount of Good $\mathrm{X}+(\mathrm{y} / \Sigma \mathrm{y}) \times \Sigma \mathrm{x}$

End of period allocation of good $\mathrm{Y}=$ Initial amount of Good $\mathrm{Y}-\mathrm{y}$ (amount offered in trade).

Notice several things.

1) If you offer to trade Good X for $Y$ or Good $Y$ for $X$, your end of period allocation of the good you are trading is always reduced by the amount you offer in trade relative to your endowment level of that good.

2) If you are the only one offering to trade a good (X or Y), then $\mathrm{x} / \Sigma \mathrm{x}$ or $\mathrm{y} / \Sigma \mathrm{y}$ will be 1 - that is, you will get 100 percent of the other good offered in trade (Y or X), if any of that good is offered. Otherwise, your fraction or share of the other good (if offered) is proportional to you relative contribution to the total supply of the good you are offering in trade, $\mathrm{x} / \Sigma \mathrm{x}$ or $\mathrm{y} / \Sigma \mathrm{y}$.

3) If you offer to trade Good X for $Y$ (Good $Y$ for $X)$ and $\Sigma y=0(\Sigma x=0)$, you do not acquire any additional units of $\mathrm{Y}(\mathrm{X})$. That is, in order to increase your end of period allocation of one good relative to your initial endowment level, there must be "supply" and "demand" on both sides of the market, that is, both $\Sigma \mathrm{y}$ and $\Sigma \mathrm{x}$ must be positive.

\section{Your Payoff Each Period}

Your payoff in points each period depends on your type and your end-of-period allocation. 
Let $x$ denote your end-of-period allocation of Good X and let $y$ denote your end-of-period allocation of Good Y.

If you are Type 1 , then your payoff in points for the period $=x^{2} \times y$.

If you are Type 2, then your payoff in points for the period $=x \times y^{2}$.

The computer program will calculate your end-of-period points for you and this number will be reported to you on your screen.

\section{Information Feedback and Record Keeping}

At the end of each period, you will be reminded of your trading decision (if any) and informed of the total amount of good $\mathrm{X}$ and good $\mathrm{Y}$ offered by all members of your group including yourself ( $\Sigma \mathrm{x}$ and $\Sigma \mathrm{y}$ ). If you offered to trade a good, you will also learn the fraction of the total amount of that good that was provided by you and the amount of the other good you acquired as the result of that trade (if any). Finally, you will be told your final allocation of good $\mathrm{X}$ and good $\mathrm{Y}$ for the period, your total points calculated using the payoff function for your type and your cash earnings for the round in the event that round is chosen for payment (as discussed below).

Following each round of play, please record this information on your record sheet under the appropriate headings.

\section{Payments}

At the end of the 25 periods played in today's session, one of the 25 periods will be chosen at random. The points you earned in that round will be converted into dollars at the rate of $\$ 1=100,000$ points. For your convenience, we report your dollar payoff for each period, but remember that only one period will be randomly chosen for actual payment in cash at the end of the session.

For your convenience, we attach two Tables, one for Type 1 and one for Type 2. These tables show the dollar payments you can earn from various end-of-period allocations using the conversion factor of 100,000 points $=\$ 1$. Notice that these tables do not include all possible or feasible payoffs, but they are comprehensive enough to give you some sense of what your payoffs would be for various end-of-period allocations you might achieve. In reading these tables notice that as you increase your end of period allocation of both goods (move down and to the right), your payoffs increase. The shaded bands in these Tables are there to help you assess payoff increases. Roughly speaking, your payoff doubles as you move down and to the right from the midpoint of one shaded band to the midpoint of the next lower band.

The computer program will convert your end of period point total into dollars and this will be reported to you on your decision screen.

Initial Endowments 
If you are Type 1 you will start each period with 10 units of Good X and 200 units of Good Y.

If you are Type 2 you will start each period with 200 units of Good X and 10 units of Good Y.

\section{Things to Consider}

1. If you choose No Trade, then your end-of-period allocation equals your initial endowment. Your payoff in points if you are Type 1 is:

$10 \times 10 \times 200=20,000$ points, and your payoff if you are Type 2 is

$200 \times 10 \times 10=20,000$ points. In either case, your dollar earnings would be

$\$(20,0000 / 100,0000)=\$ 0.20$. If you choose not to trade your payoff is certain your end-of period allocation is unaffected by the decisions of other members of your four-player group.

2. If you are Type 1, then your payoff increases over your endowment payoff if you successfully acquire more of either Good X or Good Y. As the payoff table for Type 1 players indicates, your payoff increases more rapidly if you succeed in obtaining Good X in trade (trade $\mathrm{Y}$ for $\mathrm{X}$ ) than if you succeed in obtaining Good $\mathrm{Y}$ in trade (trade Good X for $\mathrm{Y}$ ). However any increase in your payoff over your endowment payoff will depend on other players in your group offering to trade some of the good opposite to the good you are offering to trade.

3. If you are Type 2, then your payoff increases as you successfully acquire more of either Good X or Good Y. As the payoff table for Type 2 players indicates, your payoff increases more rapidly if you succeed in obtaining Good Y in trade (trade $\mathrm{X}$ for $\mathrm{Y}$ ) than if you succeed in obtaining Good $\mathrm{X}$ in trade (trade Good $\mathrm{Y}$ for $\mathrm{X}$ ). However again, any increase in your payoff over your endowment payoff will depend on other players in your group offering to trade some of the good opposite to the good you are offering to trade.

\section{Questions}

Now is the time for questions. I am happy to answer any questions about the rules of play and payoff determination as described in these instructions.

\section{$\underline{\text { Quiz }}$}

Before proceeding, we ask that you answer the attached quiz questions. You do not need to write your name on this quiz and it does not affect your payoff in any way. We just want to verify that you have comprehended these instructions. If any quiz questions are answered incorrectly, we will go over the relevant part of the instructions again. 
Pre-Experiment Quiz: Please answer the questions in the space provided. You do not need to write your name on this quiz. When you are done pass your quiz answers to the experimenter. We will review any incorrect answers before proceeding.

The numbers in these quiz questions are examples only. Actual numbers in the experiment may be quite different.

1. True or false: Your Type, 1 or 2, will be the same in all periods.

2. True or false: You must offer to trade either good X for good Y or good Y for $\operatorname{good} \mathrm{X}$.

3. Suppose you initially have 10 units of good $X$ and 200 units of good Y. If you choose to trade, what is the minimum and maximum units of good $\mathrm{X}$ can you offer in trade?

What is the minimum and maximum units of good $\mathrm{Y}$ can you offer in trade?

4. Suppose you are Type 2: You initially have 200 units of Good X and 10 units of Good Y.

a. Suppose you offer 50 units of good $X$ for good $Y$. What is your end of period allocation of good $\mathrm{X}$ ?

b. Suppose the total amount offered of good $X(\Sigma x)$ including your own contribution is 100, what is your share of the total amount of good $\mathrm{Y}(\Sigma \mathrm{y})$ ?

c. If the total amount offered of good $\mathrm{Y}(\Sigma \mathrm{y})$ is 210 , what is your end of period allocation of good Y?

d. Using your end of period allocation of goods $\mathrm{X}$ and $\mathrm{Y}$ (your answers to parts a and c), what would be your payoff in dollars for this period if it were the one chosen at random for payment?

5. Suppose you are Type 1: You initially have 10 units of Good X and 200 units of Good Y.

a. Suppose you offer 150 units of good Y for good X. What is your end of period allocation of good $\mathrm{Y}$ ?

b. Suppose the total amount offered of good $\mathrm{Y}$ including your own contribution $(\Sigma \mathrm{y})$ is 150 , what is your share of the total amount of good $\mathrm{X}$ $(\Sigma \mathrm{x})$ ?

c. If the total amount offered of good $X(\Sigma x)$ is 0 , what is your end of period allocation of good X?

d. Using your end of period allocation of goods $\mathrm{X}$ and $\mathrm{Y}$ (your answers to parts a and c), what would be your (approximate) payoff in dollars for this period if it were the one chosen at random for payment? 
[Treatment (2) involving groups of 20 players].

\section{Instructions}

Welcome to this experiment in economic decision-making. Funds for this experimental study have been provided by the University of Pittsburgh. Please read these instructions carefully as they explain how you earn money from the decisions that you make. There is NO TALKING for the duration of this experiment. If you have a question, please raise your hand.

Today's session involves 20 participants. At the start of the session, all participants will be divided up equally into one of two types, Type 1 and Type 2, so that there are precisely 10 of each type. The types differ only in their preferences for the two types of goods, Good X and Good Y, as will be explained below. Your type will be shown on your computer screen and will not change for the duration of the experiment.

\section{Sequence of Play in Each Period}

In today's experiment you will participate in 25 periods of decision-making. In each period you will make decisions that will affect outcomes for all other participants and the decisions of all other participants will affect your outcome as well. You will never know the identity of any other individual nor will they know your identity even after the session is over.

You will start the period with an initial "endowment” of Good X and of Good Y that will be shown to you on your computer screen. This initial endowment depends on your type and since your type never changes, your initial endowment will be the same at the start of each period. All participants must then simultaneously make a choice. Your choices are: 1) Trade Good X for Good Y, 2) Trade Good Y for Good X or 3) No Trade. Click on the radio button next to your choice and then click the Submit button. You can change your choice any time prior to clicking the Submit button.

If you choose options 1 or 2: Trade Good X for Good Y or Trade Good Y for Good X, then an input box will appear. In this box, you must type in the quantity of the good you wish to trade for the other good. Quantity amounts are restricted to be integers (no decimals, please). The minimum quantity you can offer to trade is 1 unit and the maximum quantity you can offer to trade is your entire endowment of that good (X or $\mathrm{Y}$ ).

If you choose option 3: No Trade, you will not participate in any trade of Good X or Y for the other good and will end the period with your initial endowment of these two goods.

\section{$\underline{\text { Your End-Of-Period Allocation }}$}

Your end-of-period-allocation is the amount of good $\mathrm{X}$ and good $\mathrm{Y}$ you have at the end of the period. This end-of-period allocation determines your payoff in points for the round as explained below. 
If you chose No Trade, your end-of-period allocation is the SAME as your initial endowment of Good X and Good Y.

If you chose to Trade Good X for Good Y, or to Trade Good Y for Good X, then your end-of-period allocation depends on the amount you offered to trade and the amounts and goods the other participants chose to trade.

Let $\Sigma \mathrm{x}$ be the total amount of good $\mathrm{x}$ offered for trade by participants including you and let $\Sigma y$ be the total amount of good $Y$ offered for trade by all participants including you.

If you chose to Trade Good X for Good Y and you offered $\mathrm{x}$ units of Good X, then your end of period allocation is determined as follows:

End of period allocation of good X = Initial amount of Good X - x (amount offered in trade).

End of period allocation of good $\mathrm{Y}=$ Initial amount of Good $\mathrm{Y}+(\mathrm{x} / \Sigma \mathrm{x}) \times \Sigma \mathrm{y}$.

If you chose to Trade Good Y for Good X and offered y units of Good Y, then your end of period allocation is determined as follows:

End of period allocation of good $\mathrm{X}=$ Initial amount of Good $\mathrm{X}+(\mathrm{y} / \Sigma \mathrm{y}) \times \Sigma \mathrm{x}$ End of period allocation of good $\mathrm{Y}=$ Initial amount of Good $\mathrm{Y}-\mathrm{y}$ (amount offered in trade).

Notice several things.

1) If you offer to trade Good $X$ for $Y$ or Good $Y$ for $X$, your end of period allocation of the good you are trading is always reduced by the amount you offer in trade relative to your endowment level of that good.

2) If you are the only one offering to trade a good ( $\mathrm{X}$ or $\mathrm{Y}$ ), then $\mathrm{x} / \Sigma \mathrm{x}$ or $\mathrm{y} / \Sigma \mathrm{y}$ will be 1 - that is, you will get 100 percent of the other good offered in trade ( $Y$ or $X)$, if any of that good is offered. Otherwise, your fraction or share of the other good (if offered) is proportional to you relative contribution to the total supply of the good you are offering in trade, $\mathrm{x} / \Sigma \mathrm{x}$ or $\mathrm{y} / \Sigma \mathrm{y}$.

3) If you offer to trade Good X for $Y$ (Good $Y$ for $X)$ and $\Sigma y=0(\Sigma x=0)$, you do not acquire any additional units of $\mathrm{Y}(\mathrm{X})$. That is, in order to increase your end of period allocation of one good relative to your initial endowment level, there must be "supply" and "demand" on both sides of the market, that is, both $\Sigma y$ and $\Sigma x$ must be positive.

\section{$\underline{\text { Your Payoff Each Period }}$}

Your payoff in points each period depends on your type and your end-of-period allocation.

Let $x$ denote your end-of-period allocation of Good X and let $y$ denote your end-of-period allocation of Good Y. 
If you are Type 1, then your payoff in points for the period $=x^{2} \times y$.

If you are Type 2, then your payoff in points for the period $=x \times y^{2}$.

The computer program will calculate your end-of-period points for you and this number will be reported to you on your screen.

\section{Information Feedback and Record Keeping}

At the end of each period, you will be reminded of your trading decision (if any) and informed of the total amount of good $\mathrm{X}$ and good $\mathrm{Y}$ offered by all participants including yourself ( $\Sigma \mathrm{x}$ and $\Sigma \mathrm{y})$. If you offered to trade a good, you will also learn the fraction of the total amount of that good that was provided by you and the amount of the other good you acquired as the result of that trade (if any). Finally, you will be told your final allocation of good $\mathrm{X}$ and good $\mathrm{Y}$ for the period, your total points calculated using the payoff function for your type and your cash earnings for the round in the event that round is chosen for payment (as discussed below).

Following each round of play, please record this information on your record sheet under the appropriate headings.

\section{$\underline{\text { Payments }}$}

At the end of the 25 periods played in today's session, one of the 25 periods will be chosen at random. The points you earned in that round will be converted into dollars at the rate of $\$ 1=100,000$ points. For your convenience, we report your dollar payoff for each period, but remember that only one period will be randomly chosen for actual payment in cash at the end of the session.

For your convenience, we attach two Tables, one for Type 1 and one for Type 2. These tables show the dollar payments you can earn from various end-of-period allocations using the conversion factor of 100,000 points $=\$ 1$. Notice that these tables do not include all possible or feasible payoffs, but they are comprehensive enough to give you some sense of what your payoffs would be for various end-of-period allocations you might achieve. In reading these tables notice that as you increase your end of period allocation of both goods (move down and to the right), your payoffs increase. The shaded bands in these Tables are there to help you assess payoff increases. Roughly speaking, your payoff doubles as you move down and to the right from the midpoint of one shaded band to the midpoint of the next lower band.

The computer program will convert your end of period point total into dollars and this will be reported to you on your decision screen.

$\underline{\text { Initial Endowments }}$ 
If you are Type 1 you will start each period with 10 units of Good X and 200 units of Good Y.

If you are Type 2 you will start each period with 200 units of Good X and 10 units of Good Y.

\section{Things to Consider}

4. If you choose No Trade, then your end-of-period allocation equals your initial endowment. Your payoff in points if you are Type 1 is:

$10 \times 10 \times 200=20,000$ points, and your payoff if you are Type 2 is $200 \times 10 \times 10=20,000$ points. In either case, your dollar earnings would be $\$(20,0000 / 100,0000)=\$ 0.20$. If you choose not to trade your payoff is certain your end-of period allocation is unaffected by the decisions of other participants.

5. If you are Type 1, then your payoff increases over your endowment payoff if you successfully acquire more of either Good X or Good Y. As the payoff table for Type 1 players indicates, your payoff increases more rapidly if you succeed in obtaining Good X in trade (trade $\mathrm{Y}$ for $\mathrm{X}$ ) than if you succeed in obtaining Good $\mathrm{Y}$ in trade (trade Good $\mathrm{X}$ for $\mathrm{Y}$ ). However any increase in your payoff over your endowment payoff will depend on other participants offering to trade some of the good opposite to the good you are offering to trade.

6. If you are Type 2, then your payoff increases as you successfully acquire more of either Good X or Good Y. As the payoff table for Type 2 players indicates, your payoff increases more rapidly if you succeed in obtaining Good $\mathrm{Y}$ in trade (trade $\mathrm{X}$ for $\mathrm{Y}$ ) than if you succeed in obtaining Good X in trade (trade Good Y for X). However again, any increase in your payoff over your endowment payoff will depend on other participants offering to trade some of the good opposite to the good you are offering to trade.

\section{Questions}

Now is the time for questions. I am happy to answer any questions about the rules of play and payoff determination as described in these instructions.

\section{Quiz}

Before proceeding, we ask that you answer the attached quiz questions. You do not need to write your name on this quiz and it does not affect your payoff in any way. We just want to verify that you have comprehended these instructions. If any quiz questions are answered incorrectly, we will go over the relevant part of the instructions again.

Pre-Experiment Quiz: Please answer the questions in the space provided. You do not need to write your name on this quiz. When you are done pass your quiz answers to the experimenter. We will review any incorrect answers before proceeding. 
The numbers in these quiz questions are examples only. Actual numbers in the experiment may be quite different.

6. True or false: Your Type, 1 or 2, will be the same in all periods.

7. True or false: You must offer to trade either good X for good $\mathrm{Y}$ or good $\mathrm{Y}$ for good $\mathrm{X}$.

8. Suppose you initially have 10 units of good X and 200 units of good Y. If you choose to trade, what is the minimum and maximum units of good $\mathrm{X}$ can you offer in trade?

What is the minimum and maximum units of good $\mathrm{Y}$ can you offer in trade?

9. Suppose you are Type 2: You initially have 200 units of Good X and 10 units of Good Y.

a. Suppose you offer 50 units of good X for good Y. What is your end of period allocation of good $\mathrm{X}$ ?

b. Suppose the total amount offered of good $X(\Sigma x)$ including your own contribution is 100, what is your share of the total amount of good Y $(\Sigma y)$ ?

c. If the total amount offered of good $\mathrm{Y}(\Sigma \mathrm{y})$ is 210 , what is your end of period allocation of good Y?

d. Using your end of period allocation of goods $\mathrm{X}$ and $\mathrm{Y}$ (your answers to parts a and c), what would be your payoff in dollars for this period if it were the one chosen at random for payment?

10. Suppose you are Type 1: You initially have 10 units of Good X and 200 units of Good Y.

a. Suppose you offer 150 units of good Y for good X. What is your end of period allocation of good Y?

b. Suppose the total amount offered of good $\mathrm{Y}$ including your own contribution $(\Sigma \mathrm{y})$ is 150 , what is your share of the total amount of good $\mathrm{X}$ $(\Sigma \mathrm{x})$ ?

c. If the total amount offered of good $X(\Sigma x)$ is 0 , what is your end of period allocation of good $X$ ?

d. Using your end of period allocation of goods $\mathrm{X}$ and $\mathrm{Y}$ (your answers to parts a and c), what would be your payoff in dollars for this period if it were the one chosen at random for payment? 
Type 1 Player Payoffs in Dollars

End of Period Y

\begin{tabular}{|c|c|c|c|c|c|c|c|c|c|c|c|c|c|c|c|c|c|c|c|}
\hline $\mathrm{X} / \mathrm{Y}$ & 10 & 15 & 25 & 35 & 45 & 55 & 65 & 75 & 85 & 95 & 105 & 115 & 125 & 135 & 140 & 150 & 200 & 250 & 300 \\
\hline 10 & 0.010 & 0.015 & 0.025 & 0.035 & 0.045 & 0.055 & 0.065 & 0.075 & 0.085 & 0.095 & 0.105 & 0.115 & 0.125 & 0.135 & 0.140 & 0.150 & 0.200 & 0.250 & 0.300 \\
\hline 15 & 0.023 & 0.034 & 0.056 & 0.079 & 0.101 & 0.124 & 0.146 & 0.169 & 0.191 & 0.214 & 0.236 & 0.259 & 0.281 & 0.304 & 0.315 & 0.338 & 0.450 & 0.563 & 0.675 \\
\hline 25 & 0.063 & 0.094 & 0.156 & 0.219 & 0.281 & 0.344 & 0.406 & 0.469 & 0.531 & 0.594 & 0.656 & 0.719 & 0.781 & 0.844 & 0.875 & 0.938 & 1.250 & 1.563 & 1.875 \\
\hline 35 & 0.123 & 0.184 & 0.306 & 0.429 & 0.551 & 0.674 & 0.796 & 0.919 & 1.041 & 1.164 & 1.286 & 1.409 & 1.531 & 1.654 & 1.715 & 1.838 & 2.450 & 3.063 & 3.675 \\
\hline 45 & 0.203 & 0.304 & 0.506 & 0.709 & 0.911 & 1.114 & 1.316 & 1.519 & 1.721 & 1.924 & 2.126 & 2.329 & 2.531 & 2.734 & 2.835 & 3.038 & 4.050 & 5.063 & 6.075 \\
\hline 55 & 0.303 & 0.454 & 0.756 & 1.059 & 1.361 & 1.664 & 1.966 & 2.269 & 2.571 & 2.874 & 3.176 & 3.479 & 3.781 & 4.084 & 4.235 & 4.538 & 6.050 & 7.563 & 9.075 \\
\hline 65 & 0.423 & 0.634 & 1.056 & 1.479 & 1.901 & 2.324 & 2.746 & 3.169 & 3.591 & 4.014 & 4.436 & 4.859 & 5.281 & 5.704 & 5.915 & 6.338 & 8.450 & 10.563 & 12.675 \\
\hline 75 & 0.563 & 0.844 & 1.406 & 1.969 & 2.531 & 3.094 & 3.656 & 4.219 & 4.781 & 5.344 & 5.906 & 6.469 & 7.031 & 7.594 & 7.875 & 8.438 & 11.250 & 14.063 & 16.875 \\
\hline 85 & 0.723 & 1.084 & 1.806 & 2.529 & 3.251 & 3.974 & 4.696 & 5.419 & 6.141 & 6.864 & 7.586 & 8.309 & 9.031 & 9.754 & 10.115 & 10.838 & 14.450 & 18.063 & 21.675 \\
\hline 95 & 0.903 & 1.354 & 2.256 & 3.159 & 4.061 & 4.964 & 5.866 & 6.769 & 7.671 & 8.574 & 9.476 & 10.379 & 11.281 & 12.184 & 12.635 & 13.538 & 18.050 & 22.563 & 27.075 \\
\hline 105 & 1.103 & 1.654 & 2.756 & 3.859 & 4.961 & 6.064 & 7.166 & 8.269 & 9.371 & 10.474 & 11.576 & 12.679 & 13.781 & 14.884 & 15.435 & 16.538 & 22.050 & 27.563 & 33.075 \\
\hline 115 & 1.323 & 1.984 & 3.306 & 4.629 & 5.951 & 7.274 & 8.596 & 9.919 & 11.241 & 12.564 & 13.886 & 15.209 & 16.531 & 17.854 & 18.515 & 19.838 & 26.450 & 33.063 & 39.675 \\
\hline 125 & 1.563 & 2.344 & 3.906 & 5.469 & 7.031 & 8.594 & 10.156 & 11.719 & 13.281 & 14.844 & 16.406 & 17.969 & 19.531 & 21.094 & 21.875 & 23.438 & 31.250 & 39.063 & 46.875 \\
\hline 135 & 1.823 & 2.734 & 4.556 & 6.379 & 8.201 & 10.024 & 11.846 & 13.669 & 15.491 & 17.314 & 19.136 & 20.959 & 22.781 & 24.604 & 25.515 & 27.338 & 36.450 & 45.563 & 54.675 \\
\hline 140 & 1.960 & 2.940 & 4.900 & 6.860 & 8.820 & 10.780 & 12.740 & 14.700 & 16.660 & 18.620 & 20.580 & 22.540 & 24.500 & 26.460 & 27.440 & 29.400 & 39.200 & 49.000 & 58.800 \\
\hline 150 & 2.250 & 3.375 & 5.625 & 7.875 & 10.125 & 12.375 & 14.625 & 16.875 & 19.125 & 21.375 & 23.625 & 25.875 & 28.125 & 30.375 & 31.500 & 33.750 & 45.000 & 56.250 & 67.500 \\
\hline 200 & 4.000 & 6.000 & 10.000 & 14.000 & 18.000 & 22.000 & 26.000 & 30.000 & 34.000 & 38.000 & 42.000 & 46.000 & 50.000 & 54.000 & 56.000 & 60.000 & 80.000 & 100.000 & 120.000 \\
\hline 250 & 6.250 & 9.375 & 15.625 & 21.875 & 28.125 & 34.375 & 40.625 & 46.875 & 53.125 & 59.375 & 65.625 & 71.875 & 78.125 & 84.375 & 87.500 & 93.750 & 125.000 & 156.250 & 187.500 \\
\hline 300 & 9.000 & 13.500 & 22.500 & 31.500 & 40.500 & 49.500 & 58.500 & 67.500 & 76.500 & 85.500 & 94.500 & 103.500 & 112.500 & 121.500 & 126.000 & 135.000 & 180.000 & 225.000 & 270.000 \\
\hline
\end{tabular}


Type 2 Player Payoffs in Dollars

End of Period Y

\begin{tabular}{|c|c|c|c|c|c|c|c|c|c|c|c|c|c|c|c|c|c|c|c|}
\hline $\mathrm{X} / \mathrm{Y}$ & 10 & 15 & 25 & 35 & 45 & 55 & 65 & 75 & 85 & 95 & 105 & 115 & 125 & 135 & 140 & 150 & 200 & 250 & 300 \\
\hline 10 & 0.010 & 0.023 & 0.063 & 0.123 & 0.203 & 0.303 & 0.423 & 0.563 & 0.723 & 0.903 & 1.103 & 1.323 & 1.563 & 1.823 & 1.960 & 2.250 & 4.000 & 6.250 & 9.000 \\
\hline 15 & 0.015 & 0.034 & 0.094 & 0.184 & 0.304 & 0.454 & 0.634 & 0.844 & 1.084 & 1.354 & 1.654 & 1.984 & 2.344 & 2.734 & 2.940 & 3.375 & 6.000 & 9.375 & 13.500 \\
\hline 25 & 0.025 & 0.056 & 0.156 & 0.306 & 0.506 & 0.756 & 1.056 & 1.406 & 1.806 & 2.256 & 2.756 & 3.306 & 3.906 & 4.556 & 4.900 & 5.625 & 10.000 & 15.625 & 22.500 \\
\hline 35 & 0.035 & 0.079 & 0.219 & 0.429 & 0.709 & 1.059 & 1.479 & 1.969 & 2.529 & 3.159 & 3.859 & 4.629 & 5.469 & 6.379 & 6.860 & 7.875 & 14.000 & 21.875 & 31.500 \\
\hline 45 & 0.045 & 0.101 & 0.281 & 0.551 & 0.911 & 1.361 & 1.901 & 2.531 & 3.251 & 4.061 & 4.961 & 5.951 & 7.031 & 8.201 & 8.820 & 10.125 & 18.000 & 28.125 & 40.500 \\
\hline 55 & 0.055 & 0.124 & 0.344 & 0.674 & 1.114 & 1.664 & 2.324 & 3.094 & 3.974 & 4.964 & 6.064 & 7.274 & 8.594 & 10.024 & 10.780 & 12.375 & 22.000 & 34.375 & 49.500 \\
\hline 65 & 0.065 & 0.146 & 0.406 & 0.796 & 1.316 & 1.966 & 2.746 & 3.656 & 4.696 & 5.866 & 7.166 & 8.596 & 10.156 & 11.846 & 12.740 & 14.625 & 26.000 & 40.625 & 58.500 \\
\hline 75 & 0.075 & 0.169 & 0.469 & 0.919 & 1.519 & 2.269 & 3.169 & 4.219 & 5.419 & 6.769 & 8.269 & 9.919 & 11.719 & 13.669 & 14.700 & 16.875 & 30.000 & 46.875 & 67.500 \\
\hline 85 & 0.085 & 0.191 & 0.531 & 1.041 & 1.721 & 2.571 & 3.591 & 4.781 & 6.141 & 7.671 & 9.371 & 11.241 & 13.281 & 15.491 & 16.660 & 19.125 & 34.000 & 53.125 & 76.500 \\
\hline 95 & 0.095 & 0.214 & 0.594 & 1.164 & 1.924 & 2.874 & 4.014 & 5.344 & 6.864 & 8.574 & 10.474 & 12.564 & 14.844 & 17.314 & 18.620 & 21.375 & 38.000 & 59.375 & 85.500 \\
\hline 105 & 0.105 & 0.236 & 0.656 & 1.286 & 2.126 & 3.176 & 4.436 & 5.906 & 7.586 & 9.476 & 11.576 & 13.886 & 16.406 & 19.136 & 20.580 & 23.625 & 42.000 & 65.625 & 94.500 \\
\hline 115 & 0.115 & 0.259 & 0.719 & 1.409 & 2.329 & 3.479 & 4.859 & 6.469 & 8.309 & 10.379 & 12.679 & 15.209 & 17.969 & 20.959 & 22.540 & 25.875 & 46.000 & 71.875 & 103.500 \\
\hline 125 & 0.125 & 0.281 & 0.781 & 1.531 & 2.531 & 3.781 & 5.281 & 7.031 & 9.031 & 11.281 & 13.781 & 16.531 & 19.531 & 22.781 & 24.500 & 28.125 & 50.000 & 78.125 & 112.500 \\
\hline 135 & 0.135 & 0.304 & 0.844 & 1.654 & 2.734 & 4.084 & 5.704 & 7.594 & 9.754 & 12.184 & 14.884 & 17.854 & 21.094 & 24.604 & 26.460 & 30.375 & 54.000 & 84.375 & 121.500 \\
\hline 140 & 0.140 & 0.315 & 0.875 & 1.715 & 2.835 & 4.235 & 5.915 & 7.875 & 10.115 & 12.635 & 15.435 & 18.515 & 21.875 & 25.515 & 27.440 & 31.500 & 56.000 & 87.500 & 126.000 \\
\hline 150 & 0.150 & 0.338 & 0.938 & 1.838 & 3.038 & 4.538 & 6.338 & 8.438 & 10.838 & 13.538 & 16.538 & 19.838 & 23.438 & 27.338 & 29.400 & 33.750 & 60.000 & 93.750 & 135.000 \\
\hline 200 & 0.200 & 0.450 & 1.250 & 2.450 & 4.050 & 6.050 & 8.450 & 11.250 & 14.450 & 18.050 & 22.050 & 26.450 & 31.250 & 36.450 & 39.200 & 45.000 & 80.000 & 125.000 & 180.000 \\
\hline 250 & 0.250 & 0.563 & 1.563 & 3.063 & 5.063 & 7.563 & 10.563 & 14.063 & 18.063 & 22.563 & 27.563 & 33.063 & 39.063 & 45.563 & 49.000 & 56.250 & 100.000 & 156.250 & 225.000 \\
\hline 300 & 0.300 & 0.675 & 1.875 & 3.675 & 6.075 & 9.075 & 12.675 & 16.875 & 21.675 & 27.075 & 33.075 & 39.675 & 46.875 & 54.675 & 58.800 & 67.500 & 120.000 & 187.500 & 270.000 \\
\hline
\end{tabular}




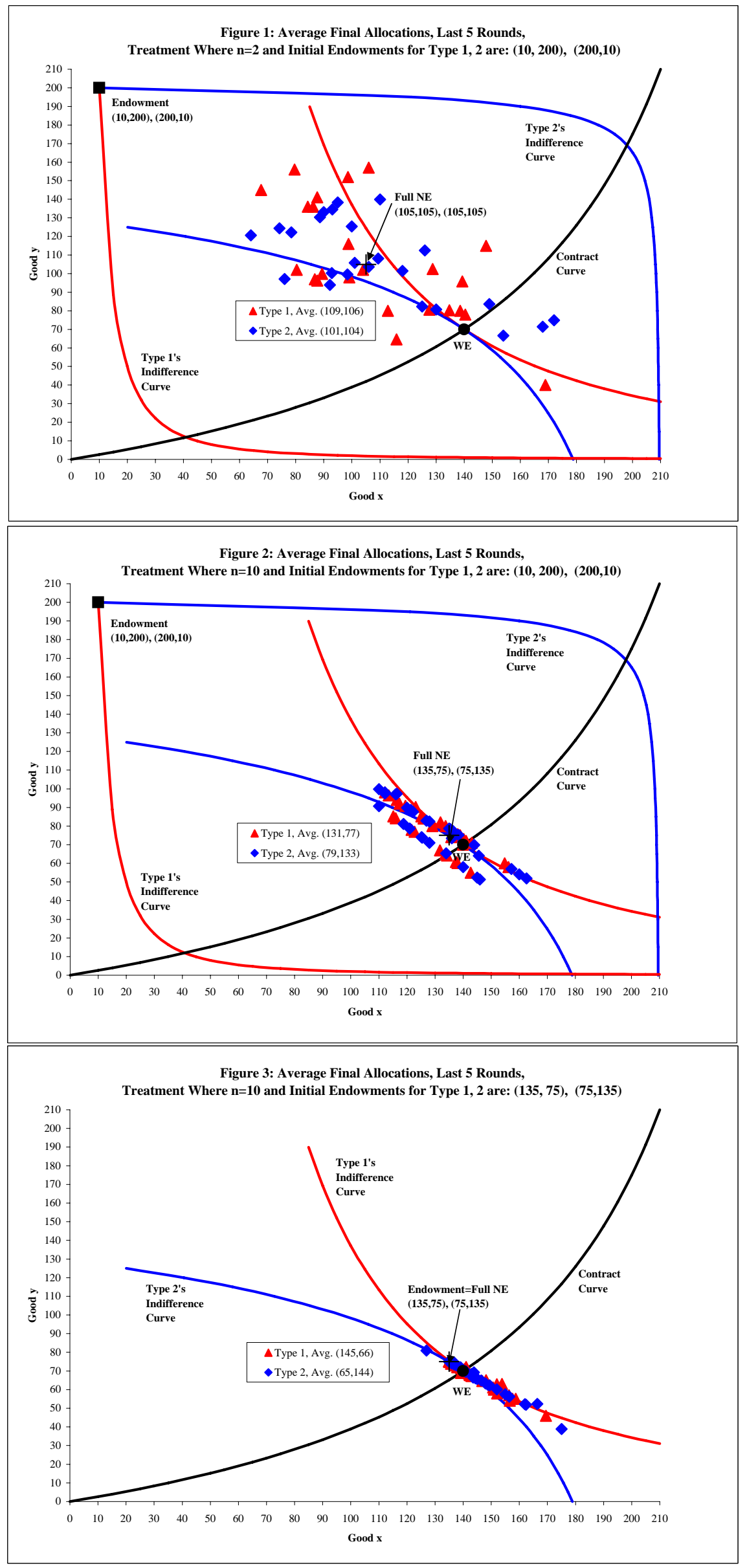




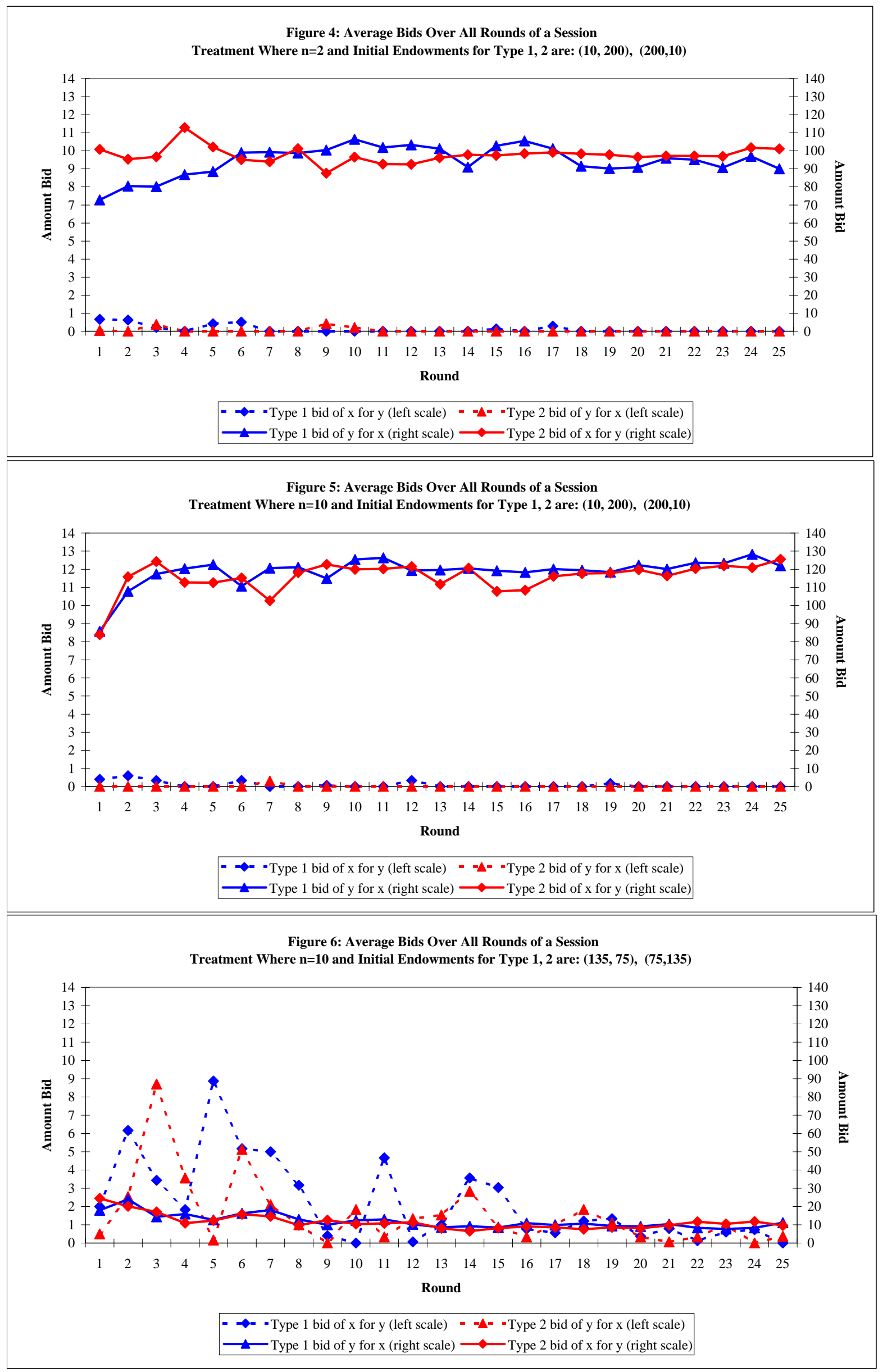




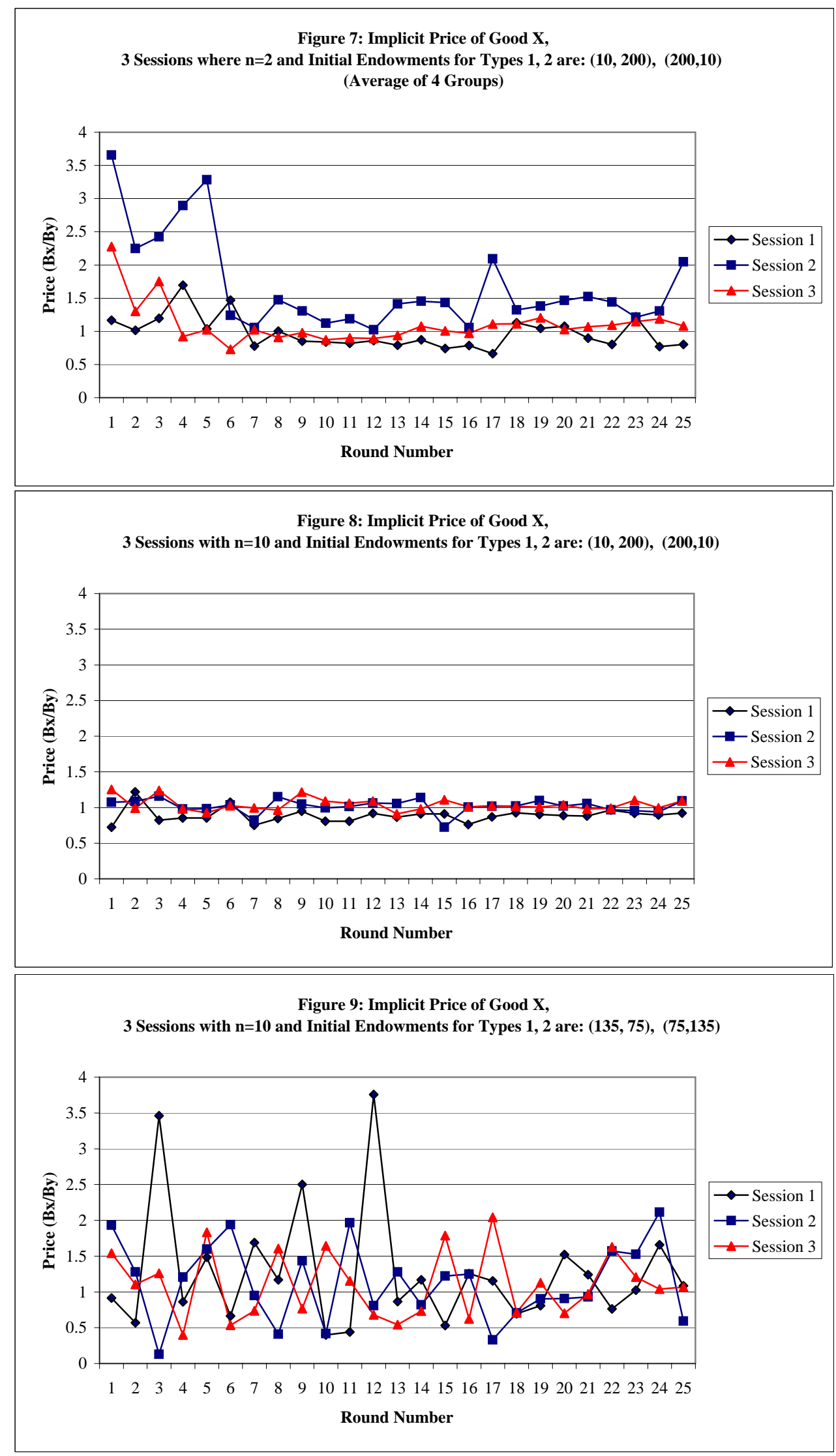

